Article

\title{
Supramolecular Assemblies of Trinuclear Copper(II)-Pyrazolato Units: A Structural, Magnetic and EPR Study
}

\author{
Kaige Shi ${ }^{1}$, Logesh Mathivathanan ${ }^{1}\left(\mathbb{D}\right.$, Radovan Herchel ${ }^{2, *}$, , Athanassios K. Boudalis ${ }^{3, *(\mathbb{D})}$ \\ and Raphael G. Raptis ${ }^{1, *(D)}$ \\ 1 Department of Chemistry and Biochemistry, Florida International University, 11200 SW 8th Street, Miami, \\ FL 33199, USA; shikaige1011@163.com (K.S.); lmathiva@fiu.edu (L.M.) \\ 2 Department of Inorganic Chemistry, Faculty of Science, Palacký University, CZ-77146 Olomouc, \\ Czech Republic \\ 3 Institut de Chimie de Strasbourg (UMR 7177, CNRS-Unistra), Université de Strasbourg, 4 rue Blaise Pascal, \\ CS 90032, F-67081 Strasbourg, France \\ * Correspondence: radovan.herchel@upol.cz (R.H.); bountalis@unistra.fr (A.K.B.); rraptis@fiu.edu (R.G.R.)
}

Received: 27 May 2020; Accepted: 17 June 2020; Published: 1 July 2020

\begin{abstract}
Two anionic complexes, $\left\{\left[\mathrm{Cu}_{3}\left(\mu_{3}-\mathrm{OH}\right)(\mu-4-\mathrm{Ph}-\mathrm{pz})_{3} \mathrm{Cl}_{3}\right]_{2}\left[\mathrm{Cu}(4-\mathrm{Ph}-\mathrm{pzH})_{4}\right](\mu-\mathrm{Cl})_{2}\right\}^{2-}(\mathbf{1})$ and $\left[\mathrm{Cu}_{3}\left(\mu_{3}-\mathrm{OH}\right)(\mu-\mathrm{pz})_{3}\left(\mu_{1,1}-\mathrm{N}_{3}\right)_{2}\left(\mathrm{~N}_{3}\right)\right]^{-}(2)$, crystallize as one-dimensional polymers, held together by weak $\mathrm{Cu}-(\mu-\mathrm{Cl})$ and $\mathrm{Cu}-\left(\mu-\mathrm{N}_{3}\right)$ interactions, respectively. Variable temperature magnetic susceptibility analyses determined the dominant antiferromagnetic intra- $\mathrm{Cu}_{3}$ exchange parameters in the solid state for both complexes, whereas the weak ferromagnetic inter- $\mathrm{Cu}_{3}$ interactions manifested also in the solid state EPR spectra, are absent in the corresponding frozen solution spectra. DFT calculations were employed to support the results of the magnetic susceptibility analyses.
\end{abstract}

Keywords: copper(II) complexes; pyrazolato ligands; supramolecular assembly; X-ray crystallography; magnetic susceptibility; EPR spectroscopy; isotropic exchange; antisymmetric exchange; dipolar interaction; DFT calculations

\section{Introduction}

Herein, we present a structural, magnetic susceptibility and EPR study of two supramolecular assemblies of metallacyclic $\mathrm{Cu}^{\mathrm{II}}$ pyrazolates with $\mathrm{Cu}_{3}\left(\mu_{3}-\mathrm{OH}\right)$ cores. The focus of this work is the elucidation of weak intermolecular interactions manifested in the magnetic properties and EPR spectra of the supramolecular assemblies.

Supramolecular interactions, such as H-bonding, dipolar, metallophilic and $\pi-\pi$ interactions, are important not only for the structural organization of molecules in $3 \mathrm{D}$, but because they often play a crucial role in determining the physical and spectroscopic properties of the assemblies. A corollary of the latter statement is that, in the absence of structural data, the detection of such spectroscopic "signatures" reveals the presence of supramolecular interactions-e.g., in biological systems. Magnetic exchange is among the properties that can be modulated by supramolecular interactions, thereby introducing new functionality into a system [1]. For instance, in the layered $\mathrm{Ni}\left(\mathrm{H}_{2} \mathrm{O}\right)_{2}\left[\mathrm{Ni}(\mathrm{CN})_{4}\right] \cdot \mathrm{xH}_{2} \mathrm{O}$ solid, $\mathrm{H}$-bonding in the interlayer regions is shown to mediate weak ferromagnetic interactions, but when the coordinated water molecules were replaced by 3-halopyridine ligands, removing $\mathrm{H}$-bonding, anti-ferromagnetic interactions through $\pi$-clouds became dominant [2]. Weak intramolecular antiferromagnetic exchange is active within a molecule containing two isolated $\mathrm{Cu}^{\mathrm{II}}$ centers separated by a $\mathrm{K}^{+}$ion, whereas relatively strong ferromagnetic interactions were found between adjacent units, along a supramolecular pathway [3]. In yet another dinuclear $\mathrm{Cu}^{\mathrm{II}}$ complex 
with chelating 2-hydroxy-1,10-phenanthroline and bridging thiocyanate ligands, it was shown that an intermolecular ferromagnetic exchange was facilitated by $\pi-\pi$ interactions between phenanthroline ligands [4-6].

The antiferromagnetic exchange among the $\mathrm{Cu}^{\mathrm{II}}$ centers of the triangular $\mathrm{Cu}_{3}\left(\mu_{3}-\mathrm{O} / \mathrm{OH}\right)$ units has been studied extensively by us and others [7-12]. We have recently turned our attention to interactions between weakly-coupled $\mathrm{Cu}_{3}\left(\mu_{3}-\mathrm{O} / \mathrm{OH}\right)$ species and shown that the presence of weak dipolar interactions str evident in the magnetic susceptibility and EPR spectra of $\mathrm{H}$-bonded $\mathrm{Cu}_{3}\left(\mu_{3}-\mathrm{OH}\right)$ units [13]. Continuing along the same lines, we report here the structure and magnetochemical studies of a heptanuclear $\mathrm{Cu}^{\mathrm{II}}$ assembly employing 4-phenyl-pyrazole ligands and of a polymeric structure containing $\mathrm{Cu}_{3} \mathrm{~N}_{6}$ metallacycles with terminal and bridging azido ligands.

\section{Materials and Methods}

\subsection{Materials}

4-Phenyl-pyrazole (4-Ph-pzH) was prepared according to a procedure from the literature [14]. All other reagents were purchased from commercial sources and used as received. Solvents were purified using standard techniques [15]. [PPN $]_{2}\left[\mathrm{Cu}_{3}\left(\mu_{3}-\mathrm{Cl}\right)_{2}(\mu-\mathrm{pz})_{3} \mathrm{Cl}_{3}\right]$ and $\left[\mathrm{PPN}_{2}\left[\mathrm{Cu}_{3}\left(\mu_{3}-\mathrm{O}\right)(\mu-\mathrm{pz})_{3} \mathrm{Cl}_{3}\right]\right.$ were prepared according to published procedures [12]; $\mathrm{PPN}^{+}=$bis(triphenylphosphine)iminium.

\subsection{Instruments}

\subsubsection{X-Ray Crystallography}

Single crystal X-ray diffraction data were collected on a Bruker D8 QUEST CMOS system equipped with a TRIUMPH curved-crystal monochromator and a fine-focus X-ray tube with graphite monochromated Mo-K $\alpha$ radiation $(\lambda=0.71073 \AA)$ at ambient or low temperature using the APEX3 or APEX2 suite [16]. Crystal data, data collection and structure refinement details are listed in Supplementary Material (Table S1). Frames were integrated with the Bruker SAINT software package using a narrow-frame algorithm. Absorption effects were corrected using the multi-scan method (SADABS) [17]. Structures were solved by intrinsic phasing methods with ShelXT [18] and refined with ShelXL [19] using full-matrix least-squares minimization using Olex2 [20]. All non-hydrogen atoms were refined anisotropically. $\mathrm{H}$ atoms were included in calculated positions riding on the $\mathrm{C}$ atoms to which they are bonded, with $\mathrm{C}-\mathrm{H}=0.93 \AA$ and Uiso(H) $=1.2$ Ueq(C). Electron densities of poorly ordered lattice solvent molecules could not be modeled satisfactorily, and they were removed by using the SQUEEZE routine in PLATON [21]. In (1), the C47 and C48 atoms were constrained to have equivalent atomic displacement parameters and the relatively large thermal ellipsoids of $C$ atoms of one of the phenyl rings (C46-C51) were restrained with enhanced rigid bond restraint [22].

\subsubsection{EPR Spectroscopy}

X-band spectra were recorded on a Bruker ESP300 spectrometer using a 4102ST rectangular cavity operating in the $\mathrm{TE}_{102}$ mode. For variable-temperature experiments the cavity was fitted in an ESR900 dynamic continuous flow cryostat and the temperature was regulated with an Oxford ITC4 servocontrol. Q-band spectra were recorded on an EMXplus spectrometer fitted with an EMX premiumQ microwave bridge and an ER5106QTW microwave resonator operating in the $\mathrm{TE}_{012}$ mode and controlled by the Bruker Xenon software. For variable-temperature experiments the resonator was fitted in an Oxford CF935 dynamic continuous flow cryostat and the temperature was regulated with an Oxford ITC503 servocontrol. The magnetic field was applied by a Bruker BE25 electromagnet using a Bruker ER082(155/45)Z power supply allowing a field sweep between -5 to 16,000 G. 


\subsubsection{Magnetic Measurements}

The temperature dependence of the magnetization at an applied field of $B=1 \mathrm{~T}$ was acquired for powder samples of (1) and (2) using PPMS Dynacool magnetometer (Quantum Design Inc., San Diego, CA, USA). The experimental data were corrected for the underlying diamagnetism and signal of the sample holder. The experimental data were fitted with program Polymagnet [23].

\subsection{Synthesis of Compounds (1) and (2)}

\subsubsection{Synthesis of $\left.[\mathrm{PPN}]_{2}\left\{\left[\mathrm{Cu}_{3}\left(\mu_{3}-\mathrm{OH}\right)(\mu-4-\mathrm{Ph}-\mathrm{pz})_{3} \mathrm{Cl}_{3}\right]_{2}\left[\mathrm{Cu}(4-\mathrm{Ph}-\mathrm{pzH})_{4}\right]\right\} \mathrm{Cl}_{2}\right\}(\mathbf{1})$}

$\mathrm{CuCl}_{2} \cdot 2 \mathrm{H}_{2} \mathrm{O}$ (0.6 mmol, $\left.102.3 \mathrm{mg}\right)$, 4-Ph-pzH (0.8 mmol, $\left.115.3 \mathrm{mg}\right), \mathrm{NaOH}(1 \mathrm{mmol}, 40 \mathrm{mg})$ and $\mathrm{PPNCl}\left(0.1 \mathrm{mmol}, 57.4 \mathrm{mg}\right.$ ) were added to $15 \mathrm{~mL} \mathrm{CH}_{3} \mathrm{CN}$ and the reaction mixture was stirred overnight. A small amount of a grey solid was filtered off and the solvent volume was reduced to $4 \mathrm{~mL}$ under reduced pressure. Suitable crystals for X-ray diffraction were grown by slow evaporation. Yield: $45 \%$ (126 mg, $0.039 \mathrm{mmol})$. Crystal data for (1): Triclinic, $P \overline{1}, \mathrm{a}=14.161(7) \AA, \mathrm{b}=17.814(8) \AA$, $c=18.173(9) \AA, \alpha=80.66(1)^{\circ}, \beta=68.33(1)^{\circ}, \gamma=85.25(1)^{\circ}, V=4202(4) \AA 3, Z=1, R_{1}=0.0661, G o F=1.020$, for 985 parameters and 17,116 observed reflections.

\subsubsection{Synthesis of $(\mathrm{PPN})\left[\mathrm{Cu}_{3}\left(\mu_{3}-\mathrm{OH}\right)(\mu-\mathrm{pz})_{3}\left(\mu_{1,1}-\mathrm{N}_{3}\right)_{2}\left(\mathrm{~N}_{3}\right)\right](2)$}

Caution! Azide complexes of metal ions in the presence of organic ligands are potentially explosive. Only small amounts should be prepared, and they should be handled with care.

A solution of $\mathrm{NaN}_{3}(0.375 \mathrm{mmol}, 24.42 \mathrm{mg})$ in $5 \mathrm{~mL}$ of $\mathrm{MeCN}$ was added dropwise to a solution of $\left[\mathrm{PPN}_{2}\left[\mathrm{Cu}_{3}\left(\mu_{3}-\mathrm{O}\right)(\mu-\mathrm{pz})_{3} \mathrm{Cl}_{3}\right](0.0628 \mathrm{mmol}, 100 \mathrm{mg})\right.$ suspended in $10 \mathrm{~mL} \mathrm{MeCN}$. The mixture was stirred overnight at rt. Well-shaped crystals suitable for $\mathrm{X}$-ray diffraction were obtained upon slow evaporation of the filtrate at room temperature over three weeks. The crystals were isolated, washed three times with methanol and ether and dried in the vacuum. Yield: $65 \%$ (44 mg, $0.041 \mathrm{mmol}$ ), based on $\mathrm{Cu}$. Anal. calcd/found for $\mathrm{C}_{45} \mathrm{H}_{40} \mathrm{Cu}_{3} \mathrm{~N}_{16} \mathrm{OP}_{2}: \mathrm{C}, 50.36 / 50.01 ; \mathrm{H}, 3.84 / 3.62 ; \mathrm{N}, 20.89 / 20.48$. Compound (2) was similarly synthesized in $\mathrm{MeOH}$ (instead of $\mathrm{MeCN}$ ), albeit with a $40 \%$ yield. Crystal data for (2): monoclinic, $P 2_{1} / c, a=8.6121(9) \AA, b=17.034(2) \AA, c=32.237(3) \AA, \beta=96.493(2)^{\circ}$, $\mathrm{V}=4698.8(8) \AA 33, \mathrm{Z}=4, \mathrm{R}_{1}=0.0662, \mathrm{GoF}=0.987$, for 623 parameters and 5601 observed reflections.

\subsection{Theoretical Calculations}

The theoretical calculations based on density functional theory (DFT) were done with ORCA 4.1 package [24] using B3LYP hybrid functional [25-27] accounting also for relativistic effects with ZORA Hamiltonian and respective ZORA-def2-TZVP basis set for $\mathrm{Cu}, \mathrm{N}, \mathrm{O}, \mathrm{Cl}$ atoms and ZORA-def2-SVP basis set for $\mathrm{C}$ and $\mathrm{H}$ atoms [28]. Additionally, the calculations utilized the chain-of-spheres (RIJCOSX) approximation to exact exchange as implemented in ORCA [29,30] and the auxiliary basis SARC/J [31]. Increased integration grids (Grid7 and Gridx7 in ORCA convention), increased radial grid (IntAcc $=8$ ) for $\mathrm{Cu}$ atoms and tight Self Consistent Field (SCF) convergence criteria were used in all calculations. The molecular fragment used in the calculations was extracted from the experimental X-ray structure. The calculated spin density was visualized with VESTA 3 program [32].

\section{Results and Discussion}

\subsection{Synthesis}

The reaction of $\mathrm{CuCl}_{2} \cdot 2 \mathrm{H}_{2} \mathrm{O}, 4-\mathrm{Ph}-\mathrm{pzH}, \mathrm{NaOH}$ and $\mathrm{PPNCl}$ in 6:9:13:1 ratio and approximately $5 \mathrm{~mL}$ of various solvents yielded the trinuclear complex, $\mathrm{PPN}\left[\mathrm{Cu}_{3}\left(\mu_{3}-\mathrm{OH}\right)(\mu-4-\mathrm{Ph}-\mathrm{pz})_{3} \mathrm{Cl}_{3}\right]$ [33]. Compound (1) was prepared from the same reagents employing a 6:6:13:1 reagent ratio in a more dilute reaction mixture $(15 \mathrm{~mL} \mathrm{MeCN})$. Pettinari et al. have obtained a similar heptanuclear complex, $\left[\left\{\mathrm{Cu}_{3}\left(\mu_{3}-\mathrm{OH}\right)(\mu-\mathrm{pz})_{3}(\mathrm{Cl})_{2}(\mathrm{Hpz})_{2}\left(\mathrm{H}_{2} \mathrm{O}\right)\right\}_{2}\left\{\mathrm{CuCl}_{2}(\mathrm{Hpz})_{2}\right\}\right]$, by acid digestion of the trinuclear $\left[\mathrm{Cu}_{3}\left(\mu_{3}-\mathrm{OH}\right)(\mu-\mathrm{pz})_{3}\left(\mathrm{CH}_{3} \mathrm{COO}\right)_{2}(\mathrm{pzH})\right]$ complex [34]. 
The azide complex (2) was synthesized in a metathesis reaction from $(\mathrm{PPN})_{2}\left[\mathrm{Cu}_{3}\left(\mu_{3}-\right.\right.$ $\mathrm{Cl})_{2}(\mu-\mathrm{pz})_{3} \mathrm{Cl}_{3}$ ] by exchanging the terminal chlorides for azide using a slight excess of $\mathrm{NaN}_{3}$ dissolved in $\mathrm{MeOH}$.

\subsection{Crystal Structure Description of $\left[P P{ }_{2}\right]_{2}\left[\left\{C u_{3}\left(\mu_{3}-\mathrm{OH}\right)(\mu-4-P h-p z)_{3} \mathrm{Cl}_{3}\right\}_{2}\left\{\mathrm{Cu}(4-\mathrm{Ph}-\mathrm{pzH})_{4}\right\}\right] C l_{2}(\mathbf{1})$}

Complex (1) crystallizes in the triclinic space group $P \overline{1}$ with the asymmetric unit containing one complete trinuclear and one-half of the mononuclear complex. Its crystal structure (Figure 1) is formed by repeating heptanuclear assemblies consisting of two trinuclear $\left[\mathrm{Cu}_{3}\left(\mu_{3}-\mathrm{OH}\right)(\mu-4-\mathrm{Ph}-\mathrm{pz})_{3} \mathrm{Cl}_{3}\right]^{-}$ anionic metallacycles on either side of a neutral, mononuclear, square planar $\left[\mathrm{Cu}(4-\mathrm{Ph}-\mathrm{pzH})_{4}\right]$; the latter is located on the crystallographic inversion center. In the solid state, two $\mathrm{Cl}$ ions act as bridges between the central mononuclear complex and the two trinuclear ones [Cl(4)- $\mathrm{Cu}(1), 2.744(2) \AA ; \mathrm{Cl}(4)-\mathrm{Cu}(4)$, 2.792(2) $\AA$ ] , occupying axial sites and forming a weakly bonded heptanuclear assembly. The two trinuclear anions contain 4-coordinate distorted square planar $\mathrm{Cu}$-centers and a pyramidal $\mu_{3}-\mathrm{OH}$ (the $\mathrm{O}$ atom is $0.473(4) \AA$ away from the $\mathrm{Cu}_{3}$-plane), have their $\mathrm{Cu}_{3}$-planes parallel to each other and are connected via two long $\mathrm{Cu}(2) \ldots \mathrm{Cl}(1)$ contacts of 3.023(2) $\AA$ to the adjacent heptanuclear unit; the $\mu-\mathrm{Cl}$ atoms occupy one equatorial and one axial position with a $\mathrm{Cu}(1)-\mathrm{Cl}(2)-\mathrm{Cu}(2)$ angle of $101.00(6)^{\circ}$. The one-dimensional chains thereby generated run parallel to the crystallographic $a$-axis (Figure 2) separated by the $\mathrm{PPN}^{+}$counterions. The long $\mathrm{Cu}(4) \ldots \mathrm{Cl}(4)$ distances of 2.792(2) $\AA$ between the mononuclear $\left[\mathrm{Cu}(4-\mathrm{Ph}-\mathrm{pzH})_{4}\right]^{2+}$ unit and the $\mu-\mathrm{Cl}$ atoms are considered as non-bonding here; however, even longer distances of 2.817-2.839 $\AA$ have been reported in the corresponding trans-[CuCl $\left.2\left(\mathrm{pz}^{*} \mathrm{H}\right)_{4}\right]$ complexes ( $\mathrm{pz}^{*} \mathrm{H}=\mathrm{pzH}$ [35], 3-tBu-pzH [36] and 3-Ph-pzH [37]). A complete list of bond lengths and angles for (1) is provided as Supplementary Material, Table S2.

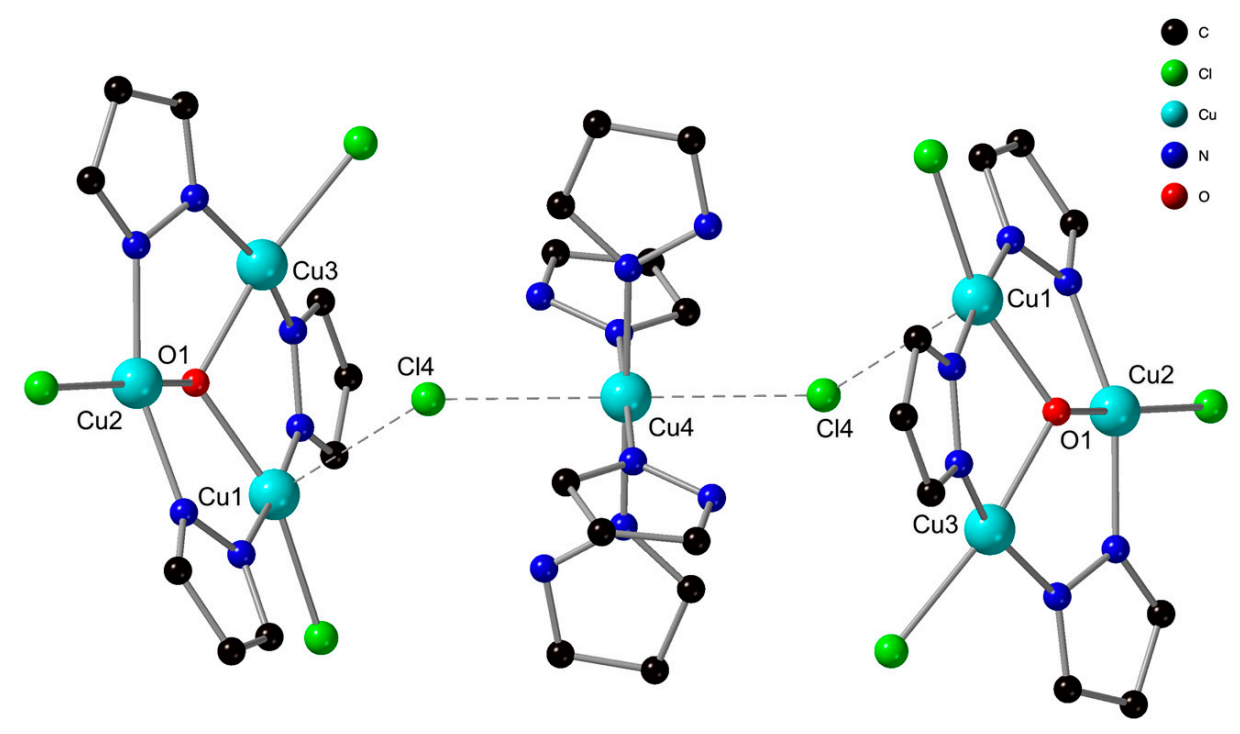

Figure 1. Crystal structure and partial atom labeling scheme of (1). Phenyl groups on the pyrazolate ligands, $\mathrm{H}$ atoms and PPN counterions are not shown for clarity. Selected interatomic distances $(\AA)$ and angles $\left({ }^{\circ}\right)$ : $\mathrm{Cu} \cdots \mathrm{Cu}, 3.243(1), 3.417(1), 3.451(2), 5.228(3)$; Cu-O, 1.990(2)-2.012(3);

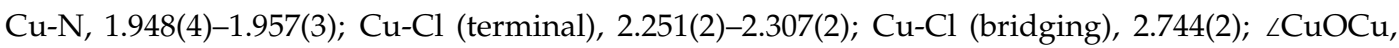
108.5(1)-118.3(2); $\angle\left(\mu_{3}-\mathrm{O}\right) \mathrm{CuCl}($ terminal), 162.6(1)-169.3(1); $\angle \mathrm{NCuN}, 160.4(1), 163.3(2)$ and 175.7(2); $\angle \mathrm{Cl}(1) \mathrm{Cu}(1) \mathrm{Cl}(4), 110.10(4)$. For the mononuclear center, $\mathrm{Cu}-\mathrm{N}, 2.017(4)$ and 2.017(4) $\AA$; $\mathrm{Cu}-\mathrm{Cl}$ (bridging), 2.792(2) $\AA ; / \mathrm{NCuN}, 91.6(1)$ and 180 . 


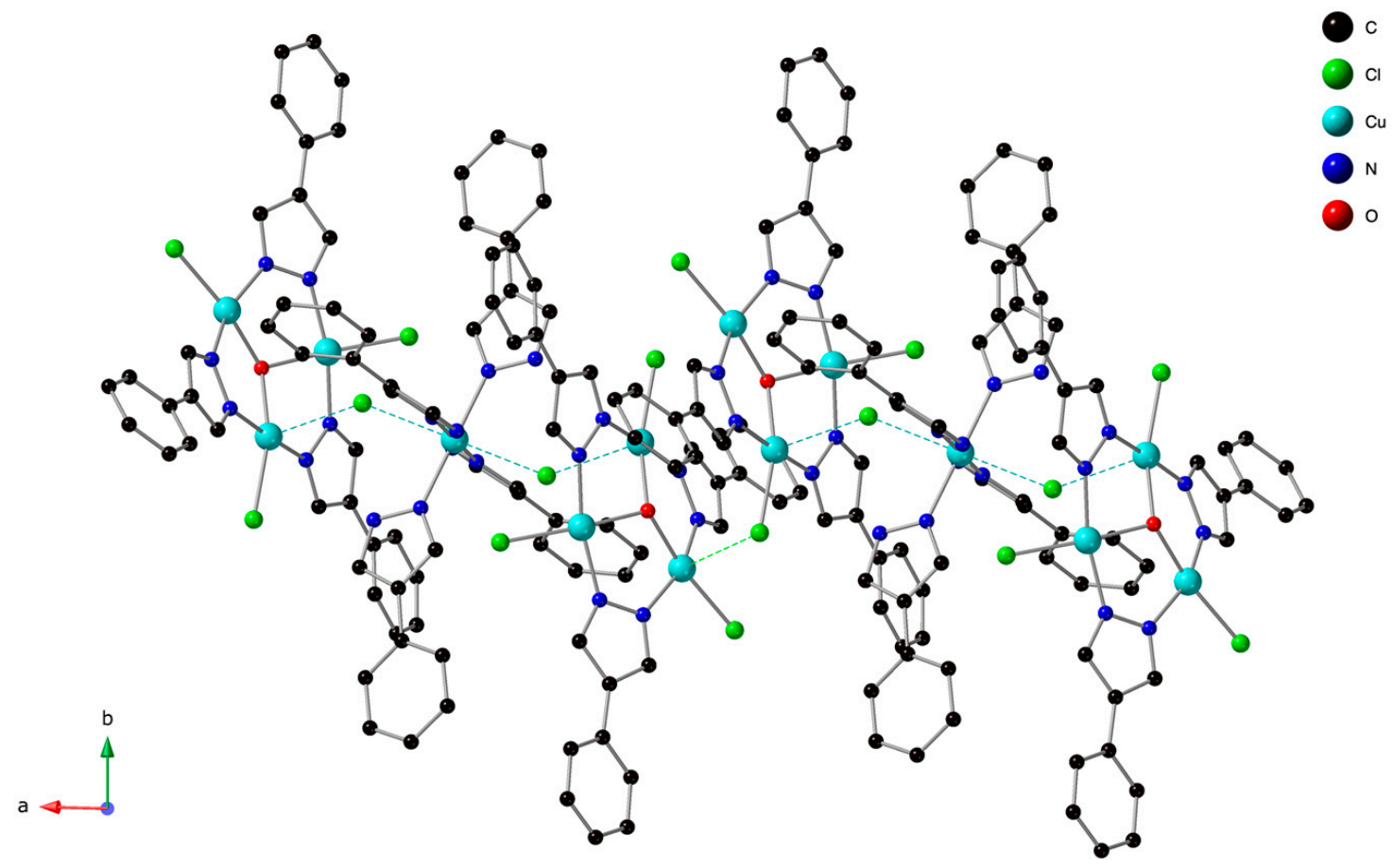

Figure 2. Molecular structure of (1) viewed parallel to the crystallographic $c$ axis showing its polymeric character. Hydrogen atoms have been omitted for clarity.

\subsection{Crystal Structure Description of (PPN) $\left[C u_{3}\left(\mu_{3}-\mathrm{OH}\right)(\mu-p z)_{3}\left(\mu, \kappa^{1,1}-N_{3}\right)_{2}\left(N_{3}\right)\right](2)$}

The complex crystallizes in the monoclinic $P 2_{1} / \mathrm{c}$ space group with the whole molecule in the asymmetric unit. The structure consists of triangular $\mu_{3}-\mathrm{OH}$-capped metallacyclic units (O atoms at $0.345(2) \AA$ from the $\mathrm{Cu}_{3}$ plane, Figure 3) connected by end-on bridging azides, forming infinite chains along the crystallographic $b$-axis (Figure 4), separated by the $\mathrm{PPN}^{+}$counterions. One of the three $\mathrm{Cu}$ centers is in square planar, whereas the other two are in distorted square pyramidal geometry. One of the three azide ligands is in a terminal monodentate coordination mode with $\mathrm{Cu}-\mathrm{N}=1.974(7) \AA$, and the other two are unsymmetrically bridging, in an end-on $\left(\mu, \mathrm{k}^{1,1}\right)$ fashion, between two $\mathrm{Cu}_{3}$ units with $\mathrm{Cu}(1)-\mathrm{N}(13)=1.980(5), \mathrm{Cu}\left(2^{\prime}\right)-\mathrm{N}(13)=2.421(5)$ and $\mathrm{Cu}(2)-\mathrm{N}(3)=2.001(5) \AA$, $\mathrm{Cu}\left(1^{\prime}\right)-\mathrm{N}(3)=2.322(5) \AA$ at each bridgehead $\mathrm{N}$, respectively. The bridging azides occupy one equatorial (shorter $\mathrm{Cu}-\mathrm{N}$ bond) and one axial (longer $\mathrm{Cu}-\mathrm{N}$ bond) at either side. The corresponding $\mathrm{Cu}-\mathrm{N}_{\mathrm{azide}}-\mathrm{Cu}$ angles are 105.9(2) and $115.0(2)^{\circ}$, respectively, holding the $\mathrm{Cu}$ atoms at intermolecular distances of 3.386(1) $\AA$ and 3.470(1) $\AA$. As expected, in the two tetragonal pyramidal Cu-centers, the axial Cu-N bonds are significantly longer than the equatorial ones. The azide ions are approximately linear with $\mathrm{N}-\mathrm{N}-\mathrm{N}$ angles of $176.7(7)^{\circ}$ and $178.3(7)^{\circ}$; contain unequal $\mathrm{N}-\mathrm{N}$ bond lengths, longer at the end involving the donor atoms, N3-N4 = 1.191(7) $\AA$ and longer at the dangling end, N4-N5 = 1.144(7) $\AA$ [38]. A complete list of bond lengths and angles for (2) is provided as Supplementary Material, Table S3. 

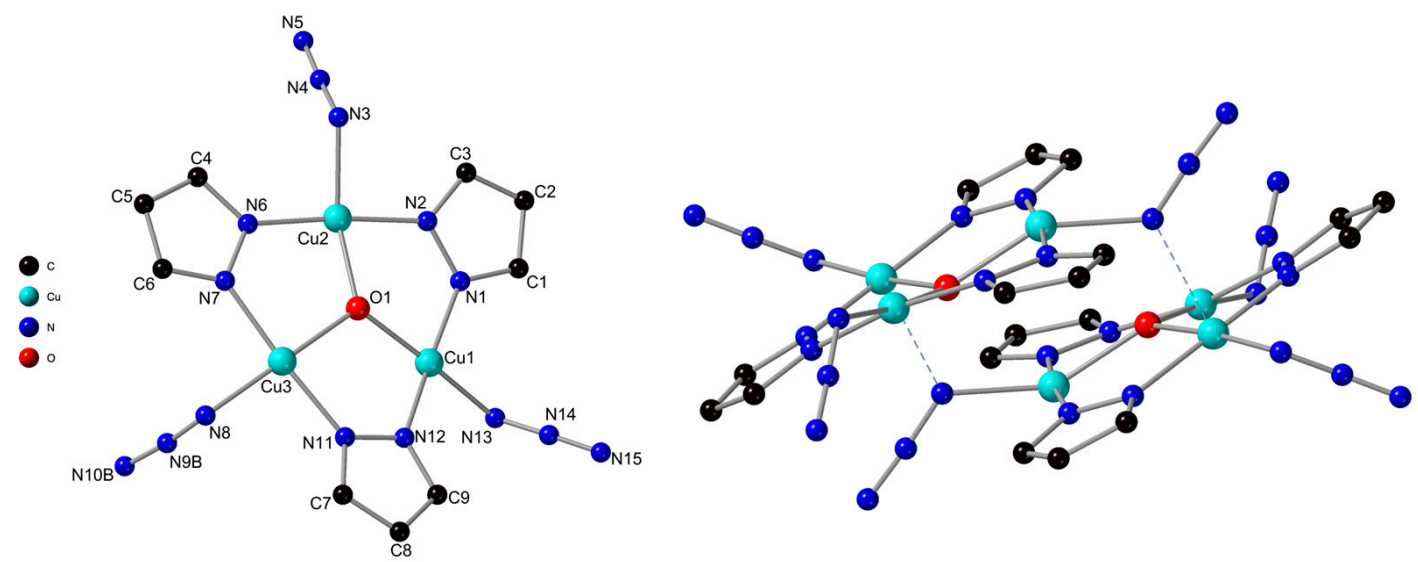

Figure 3. Asymmetric unit of (2) (left). Inter- $\mathrm{Cu}_{3}$ contacts (right). $\mathrm{H}$ atoms, disordered azide ligand and PPN counterion are not shown for clarity. Selected interatomic distances $(\AA)$ and angles $\left(^{\circ}\right): \mathrm{Cu} \cdots \mathrm{Cu}, 3.386(1), 3.389(1), 3.470(1) ; \mathrm{Cu}-\mathrm{O}, 1.976(4), 2.000(4), 2.023(4) ; \mathrm{Cu}_{\mathrm{N} z}, 1.935(5)-1.974(5)$; Cu-N $N_{\text {azide }}, 1.974(6), 1.980(5), 2.001(5) ; \angle \mathrm{CuOCu}, 115.8(2), 116.8(2), 119.1(2)$.

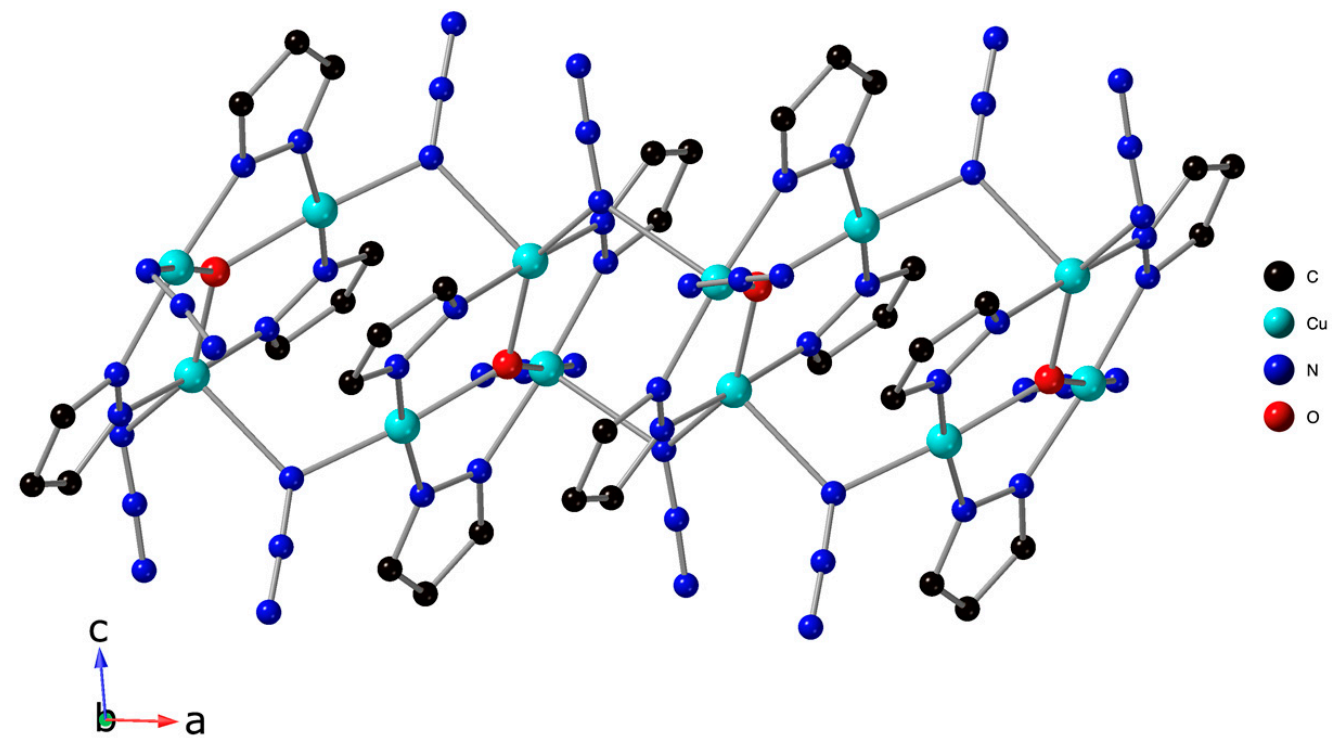

Figure 4. Packing diagram of compound (2) shown along the crystallographic $b$-axis.

\subsection{Infrared Spectra}

The coordination mode of azides to a transition metals is usually characterized by an intense IR band due to $v_{a s}\left(\mathrm{~N}_{3}\right)$ at $2000-2055 \mathrm{~cm}^{-1}$ for a terminal and $>2055 \mathrm{~cm}^{-1}$ for a bridging $\mathrm{N}_{3}-$; the larger values correspond to anions with unsymmetrical $\mathrm{N}-\mathrm{N}-\mathrm{N}$ bonding [39]. A broad trifurcated band with peaks at 2034, 2046 and $2060 \mathrm{~cm}^{-1}$ in the solid state spectrum of (2) (Figure S3) is attributed to the presence of both terminal and bridging azides.

\subsection{Magnetic Susceptibility of (1)}

The temperature dependence of the effective magnetic moment and the molar magnetization data for (1) are shown in Figure 5. The effective magnetic moment at room temperature is $4.3 \mu_{\mathrm{B}}$ and is rapidly decreasing, reaching a plateau of $3.6 \mu_{\mathrm{B}}$ at ca. $100 \mathrm{~K}$, and then further decreasing below $30 \mathrm{~K}$ to $3.1 \mu_{\mathrm{B}}$ at $1.9 \mathrm{~K}$. The theoretical spin-only value for seven non-interacting $\mathrm{Cu}^{\mathrm{II}}$ ions with $g=2.0$ is $4.58 \mu_{\mathrm{B}}$, but usually the g-factor for this ion is much larger due to the angular orbital momentum contribution, so an even larger theoretical spin-only value is expected. The lower room temperature value of $\mu_{\text {eff }}$ together with its sharp decrease on subsequent cooling thus reflect strong antiferromagnetic exchange. Such strong antiferromagnetic exchange within each $\mathrm{Cu}_{3}\left(\mu_{3}-\mathrm{OH}\right)$ triangle 
leads to $S_{\mathrm{Cu1}-2-3}=1 / 2$ ground spin state. Therefore, the value of $\mu_{\mathrm{eff}} / \mu_{\mathrm{B}} \approx 3.6$ in the temperature interval $50-120 \mathrm{~K}$ can be explained by considering coexistence of two $S_{\mathrm{Cu1-2-3}}=1 / 2$ and one $S_{\mathrm{Cu} 4}=1 / 2$ spin levels. A further decrease of $\mu_{\text {eff }}$ below $50 \mathrm{~K}$ is then ascribed to weak magnetic interactions between two $\mathrm{Cu}_{3}\left(\mu_{3}-\mathrm{OH}\right)$ triangles and eventually between $\mathrm{Cu}_{3}\left(\mu_{3}-\mathrm{OH}\right)$ triangles and the central $\left[\mathrm{Cu}(4-\mathrm{Ph}-\mathrm{pzH})_{4}\right]$ complex units (see Figure 2). Moreover, another important origin of decrease of $\mu_{\text {eff }}$ below $50 \mathrm{~K}$ can be attributed to the antisymmetric exchange interactions (ASE, also named Dzyaloshinsky-Moriya interactions) within two $\mathrm{Cu}_{3}\left(\mu_{3}-\mathrm{OH}\right)$ triangles, as this kind of interaction is typical of triangular molecular systems based on Kramers ions coupled with strong antiferromagnetic exchange [40]. Moreover, an ASE has been identified and quantified in similar coordination compounds with individual $\mathrm{Cu}_{3}\left(\mu_{3}-\mathrm{OH}\right)$ or $\mathrm{Cu}_{3}\left(\mu_{3}-\mathrm{O}\right)$ motifs, and its effects on magnetic and spectroscopic properties have been demonstrated [7,41]. Additionally, the presence of ASE in (1) was evidenced by low temperature EPR spectroscopy, as discussed in the following section. Therefore, the following spin Hamiltonian has been postulated in order to quantitatively analyze the experimental magnetic data

$$
\begin{aligned}
& \hat{H}=-J_{12}\left(\mathbf{S}_{1} \cdot \mathbf{S}_{2}+\mathbf{S}_{1}, \mathbf{S}_{2 \prime}\right)-J_{13}\left(\mathbf{S}_{1} \cdot \mathbf{S}_{3}+\mathbf{S}_{1}, \mathbf{S}_{3 \prime}\right)-J_{23}\left(\mathbf{S}_{2} \cdot \mathbf{S}_{3}+\mathbf{S}_{2 \prime} \cdot \mathbf{S}_{3 \prime}\right)-J_{12}\left(\mathbf{S}_{1} \cdot \mathbf{S}_{2 \prime}+\mathbf{S}_{1}, \mathbf{S}_{2}\right)-J_{14}\left(\mathbf{S}_{1} \cdot \mathbf{S}_{4}+\mathbf{S}_{1}, \mathbf{S}_{4}\right) \\
& +\mathbf{d}_{12} \cdot\left(\mathbf{S}_{1} \times \mathbf{S}_{2}+\mathbf{S}_{1}, \times \mathbf{S}_{2 \prime}\right)+\mathbf{d}_{23} \cdot\left(\mathbf{S}_{2} \times \mathbf{S}_{3}+\mathbf{S}_{2 \prime} \times \mathbf{S}_{3 \prime}\right)+\mathbf{d}_{31} \cdot\left(\mathbf{S}_{3} \times \mathbf{S}_{1}+\mathbf{S}_{3 \prime} \times \mathbf{S}_{1 \prime}\right)+\mu_{\mathrm{B}} \sum_{i=1}^{7} \mathbf{B} \cdot g \cdot \mathbf{S}_{i}
\end{aligned}
$$

where the isotropic exchange, Zeeman terms and ASE expressed by $\mathbf{d}_{i j}$ vectors, $\left(d_{x}, d_{y}, d_{z}\right)_{i j}$, are included. The application of Moriya symmetry rules [42] for the $\mathrm{Cu}_{3}\left(\mu_{3}-\mathrm{OH}\right)$ triangles results in only one non-zero component: $\mathbf{d}_{i j}=\left(0,0, d_{z}\right)_{i j}$ and it was assumed that $\left(d_{z}\right)_{i j}$ are equal for all pairs. Next, the molar magnetization in the direction of the magnetic field $\mathbf{B}_{a}=B \cdot(\sin \theta \cos \varphi, \sin \theta \sin \varphi, \cos \theta)$ was calculated as

$$
M_{a}=N_{\mathrm{A}} k T \frac{\partial \ln Z}{\partial B_{a}}
$$

and since the magnetic data were acquired on a polycrystalline sample, the powder average of the molar magnetization was then calculated as

$$
M_{\mathrm{mol}}=1 / 4 \pi \int_{0}^{2 \pi} \int_{0}^{\pi} M_{a} \sin \theta d \theta d \varphi
$$

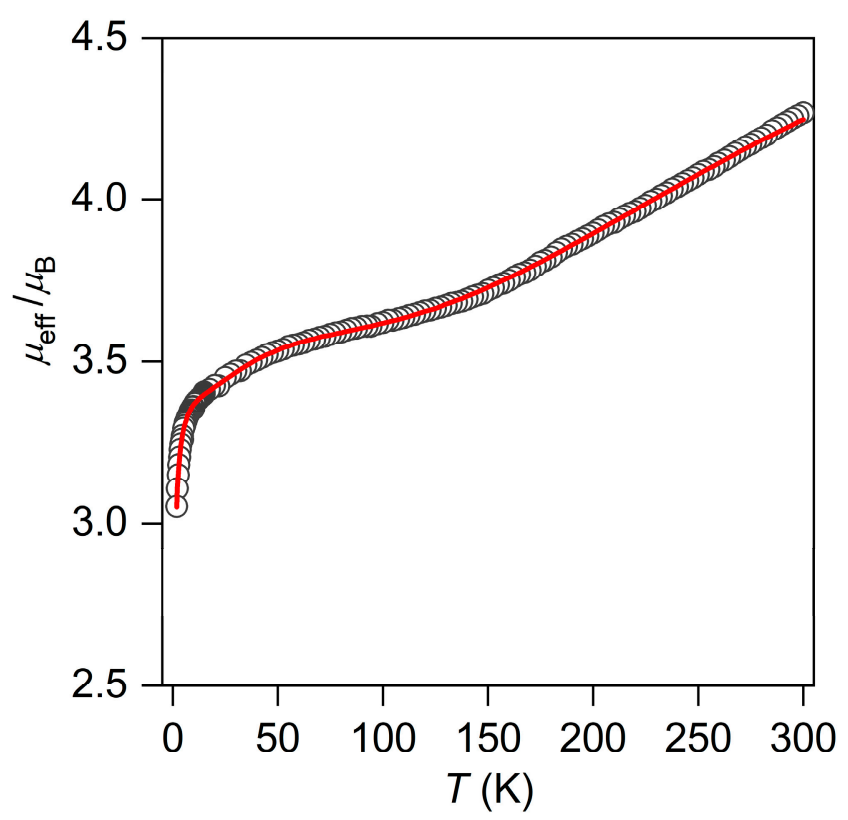

Figure 5. Temperature dependence of the effective magnetic moment for 1 . Empty circles-experimental data, full lines-calculated data with the spin Hamiltonian in Equation (1) and $J_{12}=J_{23}=-281 \mathrm{~cm}^{-1}$, $J_{13}=-226 \mathrm{~cm}^{-1}, J_{12^{\prime}}=J_{14}=+19.7 \mathrm{~cm}^{-1},\left|d_{z}\right|=37.1 \mathrm{~cm}^{-1}, g=2.35$. 
In order to reduce the number of free parameters, DFT calculations were employed (vide infra) from which we may assume $J_{12} \approx J_{23},\left|J_{12}\right|,\left|J_{23}\right|>\left|J_{13}\right|$ and $J_{12^{\prime}} \approx J_{14}$, and $J_{12^{\prime}}, J_{14}>0$. Thus, magnetic data were fitted under the assumption that magnetic coupling through $\mu$-Cl-ligands between two $\mathrm{Cu}_{3}\left(\mu_{3}-\mathrm{OH}\right)$ triangles and between $\mathrm{Cu}_{3}\left(\mu_{3}-\mathrm{OH}\right)$ triangles and the central $\left[\mathrm{Cu}(4-\mathrm{Ph}-\mathrm{pzH})_{4}\right]$ complex unit is weakly ferromagnetic, whereas the strong antiferromagnetic exchange was expected within $\mathrm{Cu}_{3}\left(\mu_{3}-\mathrm{OH}\right)$ triangles. Such analysis resulted in best-fit values of $J_{12}=J_{23}=-281 \mathrm{~cm}^{-1}$, $J_{13}=-226 \mathrm{~cm}^{-1}, J_{12^{\prime}}=J_{14}=+19.7 \mathrm{~cm}^{-1}$ and $\left|d_{z}\right|=37.1 \mathrm{~cm}^{-1}$ with an isotropic $g_{\text {-factor } g}=2.35$ (Figure 5). The temperature-independent paramagnetism was also accounted for by adding a constant term $\chi_{\mathrm{TIP}}=5.23 \times 10^{-9} \mathrm{~m}^{3} \mathrm{~mol}^{-1}$ for seven copper atoms based on the generally accepted value for one $\mathrm{Cu}^{\mathrm{II}}$ ion equal to $60 \times 10^{-6} \mathrm{~cm}^{3} \mathrm{~mol}^{-1}$ in cgs units [43], or $0.754 \times 10^{-9} \mathrm{~m}^{3} \mathrm{~mol}^{-1}$ in SI units. In summary, the strong antiferromagnetic exchange within the $\mathrm{Cu}_{3}\left(\mu_{3}-\mathrm{OH}\right)$ triangles was confirmed together with the antisymmetric non-Heisenberg interaction, and the overall analysis was impossible without the introduction of a weak inter-triangle magnetic exchange.

The value of the magnetic exchange within the $\mathrm{Cu}_{3}\left(\mu_{3}-\mathrm{OH}\right)$ triangles is comparable to those reported in the literature for similar $\mathrm{Cu}^{\mathrm{II}}$-pyrazolato/triazolato-bridged complexes containing $\mu_{3}-\mathrm{OH}$ group. It seems that in compound (1) reported herein, the antiferromagnetic exchange is one of the strongest (Table 1) [44].

Table 1. Selected magnetostructural data for various $\mathrm{Cu}_{3}\left(\mu_{3}-\mathrm{O}(\mathrm{H} / \mathrm{R})\right)$ systems.

\begin{tabular}{|c|c|c|c|}
\hline Compound $^{a}$ & $\mathrm{Cu} \cdots \mathrm{Cu}(\AA)$ & $-J,-z J^{\prime} / \mathrm{cm}^{-1}$ & Ref. \\
\hline$\left[\mathrm{Cu}^{3}(\mathrm{OH})(\mathrm{pz}) 3(\mathrm{Hpz}) 2\left(\mathrm{NO}^{3}\right)^{2}\right] \cdot \mathrm{H}^{2} \mathrm{O}$ & 3.351 & 200,0 & [45] \\
\hline$\left[\mathrm{Cu}^{3}(\mathrm{OH})(\mathrm{pz}) 3(\mathrm{py}) 2 \mathrm{Cl}^{2}\right] \cdot \mathrm{py}$ & $3.112-3.321$ & 140,0 & [46] \\
\hline$\left[\mathrm{Cu}^{3}(\mathrm{OH})(\mathrm{aat})_{3}\left(\mathrm{CF}^{3} \mathrm{SO}^{3}\right)\left(\mathrm{H}^{2} \mathrm{O}\right)\right]\left(\mathrm{CF}^{3} \mathrm{SO}^{3}\right)$ & 3.355 & $197.7,0$ & [47] \\
\hline$\left[\mathrm{Cu}^{3}(\mathrm{OH})(\right.$ aat $\left.) 3\left(\mathrm{NO}^{3}\right)\left(\mathrm{H}^{2} \mathrm{O}\right)^{2}\right]\left(\mathrm{NO}^{3}\right) \cdot\left(\mathrm{H}^{2} \mathrm{O}\right)^{2}$ & 3.341 & $190.9,0$ & [47] \\
\hline$\left[\mathrm{Cu}_{3}(\mathrm{OH})(\text { aat })_{3}\left(\mathrm{ClO}_{4}\right)\left(\mathrm{H}_{2} \mathrm{O}\right)_{2}\right]\left(\mathrm{ClO}_{4}\right)$ & 3.371 & $198.2,0$ & [47] \\
\hline$\left.\left\{\left[\mathrm{Cu}_{3}(\mathrm{O}) \text { (triazolate }\right)_{3}(\mathrm{OH})\left(\mathrm{H}_{2} \mathrm{O}\right)_{6}\right]\right\}_{n}$ & 3.388 & $112.6,11.6$ & [48] \\
\hline$\left[\mathrm{Cu}_{3}(\text { triazolate })_{3}(\mathrm{OH})\right]\left[\mathrm{Cu}_{2} \mathrm{Br}_{4}\right]$ & 3.502 & 180,68 & [49] \\
\hline$\left[\mathrm{Cu}_{3} \mathrm{Br}(\mathrm{Hpz})_{2}(\mathrm{pz})_{3}\left(\mathrm{OCH}_{3}\right)\right] \mathrm{Br}$ & $3.250-3.255$ & 105,0 & [50] \\
\hline$\left[\mathrm{Cu}_{3}(\mathrm{OH})(\text { aaat })_{3}\left(\mathrm{H}_{2} \mathrm{O}\right)_{3}\right]\left(\mathrm{NO}_{3}\right)_{2} \cdot \mathrm{H}_{2} \mathrm{O}$ & $3.347-3.393$ & 195,0 & [8] \\
\hline$\left\{\left[\mathrm{Cu}_{3}(\mathrm{OH})(\text { aat })_{3}\left(\mathrm{SO}_{4}\right)\right] \cdot 6 \mathrm{H}_{2} \mathrm{O}\right\}_{n}$ & $3.337-3.364$ & 185,0 & [8] \\
\hline$\left[\mathrm{Cu}_{3}(\operatorname{admtrz})_{4}(\mathrm{SCN})_{3}(\mathrm{OH})\left(\mathrm{H}_{2} \mathrm{O}\right)\right]\left(\mathrm{ClO}_{4}\right)_{2} \cdot \mathrm{H}_{2} \mathrm{O}$ & $3.254-3.318$ & 120,53 & [51] \\
\hline$\left[\left\{\mathrm{Cu}_{3}(\mathrm{OH})(\mathrm{pz})_{3}(\mathrm{Hpz})_{3}\right\}_{2} \mathrm{SO}_{4}\right]\left(\mathrm{NO}_{3}\right)_{2} \cdot \mathrm{MeCN} \cdot \mathrm{MeOH} \cdot 1.5 \mathrm{H}_{2} \mathrm{O}$ & $3.182-3.354$ & $180,12.7$ & [44] \\
\hline$\left[\mathrm{Ag}(\mathrm{Hpz})_{2}\right]_{2}\left[\left\{\mathrm{Ag}_{2}(\mathrm{Hpz})_{2}\left(\mathrm{NO}_{3}\right)_{2}\right\}\left\{\mathrm{Cu}_{6}(\mathrm{OH})_{2}(\mathrm{pz})_{6}(\mathrm{Hpz})_{6}\left(\mathrm{SO}_{4}\right)\right\}_{2}\right]\left(\mathrm{NO}_{3}\right)_{6} \cdot 4 \mathrm{H}_{2} \mathrm{O}$ & $3.222-3.356$ & $134,10.5$ & [44] \\
\hline$\left[\left\{\mathrm{Ag}\left(\mathrm{H}_{2} \mathrm{O}\right)_{2}\right\}\left\{\mathrm{Cu}_{3}(\mathrm{OH})(\mathrm{pz})_{3}(\mathrm{Hpz})_{3}\left(\mathrm{H}_{2} \mathrm{O}\right)\left(\mathrm{ClO}_{4}\right)_{3}\right\}\right]$ & $3.302-3.372$ & $158,9.2$ & [44] \\
\hline$\left[\mathrm{Et}_{3} \mathrm{NH}\right]\left[\mathrm{Cu}_{3}(\mathrm{OH})(\mathrm{pz})_{3}(\mathrm{PhCOO})_{3}\right]$ & $3.244-3.352$ & $178,57.5$ & [13] \\
\hline
\end{tabular}

${ }^{a}$ aat = 3-acetylamino-1,2,4-triazolate; Haaat = 3-acetylamino-5-amino-1,2,4-triazolate; admtrz = 4-amino-3,5dimethyl-1,2,4-triazole.

\subsection{EPR Spectroscopy of (1)}

Solid state X-band EPR spectra of (1) at $4.2 \mathrm{~K}$ showed a complex derivative signal centered around $3000 \mathrm{G}$, with broad linewidths and a broad resonance around $3800 \mathrm{G}(\mathrm{g} \sim 1.8)$, all characteristic of an exchange-coupled system (Figure 6). Upon heating, part of the signal decreased in intensity, leaving an axial signal, which persisted unchanged up to $290 \mathrm{~K}$, and was assigned to the central $\left[\mathrm{Cu}(4-\mathrm{Ph}-\mathrm{pzH})_{4}\right]^{2+}$ complex, which appears not to be exchange-coupled to the two $\mathrm{Cu}_{3}$ triangles. This is in agreement with the crystal structure, showing that the main coupling pathway between $\left[\mathrm{Cu}(4-\mathrm{Ph}-\mathrm{pzH})_{4}\right]$ and the trinuclear units- $\mathrm{Cl}$-counterions at axial sites on either side of the $\mathrm{Cu}_{3}$-units-involves non-magnetic orbitals $\left(\mathrm{d}_{\mathrm{z}}{ }^{2}\right)$ and consistent with the analysis of magnetic susceptibility data, where $J_{14}$ was shown to be the weakest interaction (vide supra, Section 3.5). Whereas the relaxation rate of the intradoublet signal of the $\mathrm{Cu}_{3}$ accelerates rapidly with increasing temperature, the signal intensity of the mononuclear complex follows a Curie dependence, masking the contribution of the exchange-coupled system above $12 \mathrm{~K}$. Attempts to increase the signal of the exchange-coupled system by exploiting the relaxation differences of the two components, in particular by increasing the microwave power at the low-temperature limit of the apparatus, failed; experiments at $4.0 \mathrm{~K}$ with microwave power of $20 \mathrm{~mW}$ did not selectively increase the signal intensity of that component. 


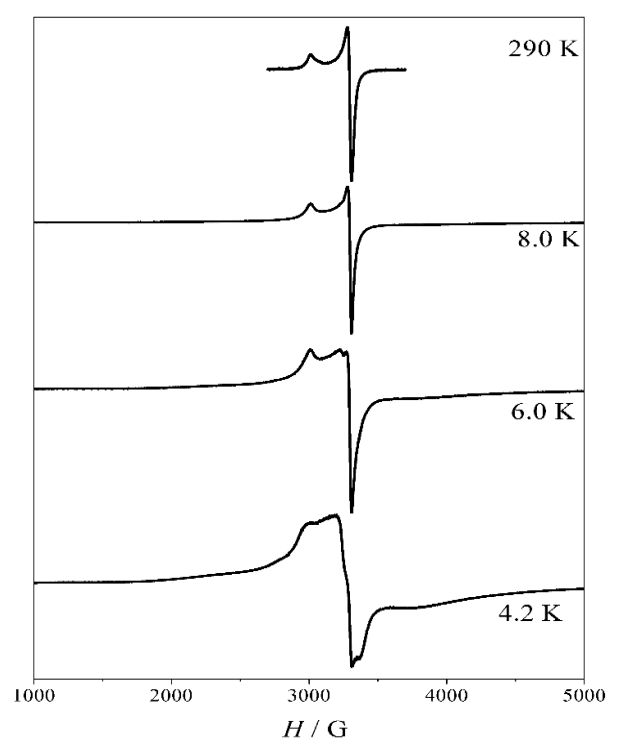

Figure 6. Solid-state X-band EPR spectra of (1) between 4.2 and $290 \mathrm{~K}$. Experimental conditions: $f_{\mathrm{EPR}}=9.43 \mathrm{GHz}, \mathrm{MA}=2 \mathrm{G}_{\mathrm{pp}}(6-290 \mathrm{~K})$ and $1 \mathrm{G}_{\mathrm{pp}}(4.2 \mathrm{~K}), P_{M W}=2 \mathrm{~mW}(6-290 \mathrm{~K})$ and $0.2 \mathrm{~mW}(4.2 \mathrm{~K})$.

The above assignment is further corroborated by EPR studies in a frozen THF solution (Figure 7) showing significant differences between the signal attributed to the two components: one axial signal exhibited hyperfine features and the other exhibited a very broad $g_{\perp}<2$ feature. The latter feature is characteristic of half-integer trinuclear clusters and is due to the presence of magnetic asymmetries operating in tandem with antisymmetric exchange [52,53]. These characteristic features allowed simulations assuming two axial subcomponents. For the former, an $s=1 / 2$ spin, described by the $\hat{H}=\beta \mathbf{H} \widehat{g} \hat{\mathbf{S}}+\hat{\mathbf{I}} \tilde{\mathbf{A}} \hat{\mathbf{S}}$ Hamiltonian, and for the latter an effective $S=1 / 2$ spin, described by a simple Zeeman Hamiltonian, were assumed. Simulations with parameters $g_{1 \perp}=2.145, g_{1 \|}=2.334, A_{1 \|}=527(\mathrm{MHz})$, $g_{2 \perp}=1.82(\mathrm{~g}$-strain $=0.37 \mathrm{FWHM})$ and $g_{2 \|}=2.268$ (relative intensities $\left.I_{2}: I_{1}=0.91: 1\right)$ gave a satisfactory agreement to the experimental spectrum. Due to the large number of variables, the above parameter set is indicative, as far as line widths and $g$-strain parameters are concerned.

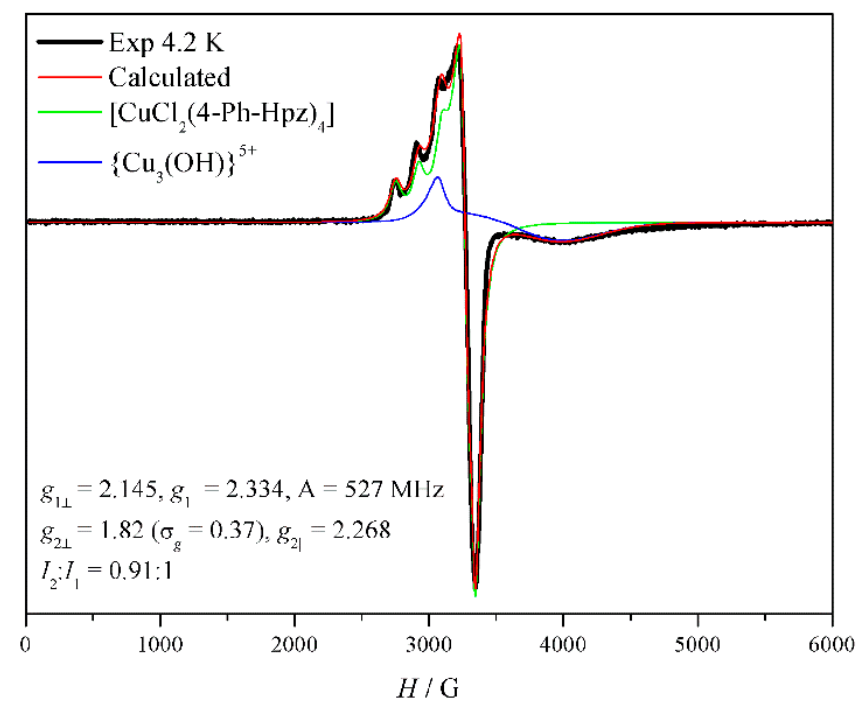

Figure 7. X-band EPR spectra of (1) in a frozen THF solution (black line) and calculated curve according to the discussion in the text (red line). The blue and green lines correspond to the two components. Experimental conditions: $f_{\mathrm{EPR}}=9.42 \mathrm{GHz}, \mathrm{MA}=2 \mathrm{G}_{\mathrm{pp}}, P_{\mathrm{MW}}=2 \mathrm{~mW}$. 
The presence of the hyperfine signals in solution and not in the solid state for the mononuclear component suggests the presence of dipolar interactions that are removed upon dissolution. To test this hypothesis and better understand the solid-state spectra of (1), complementary Q-band studies were carried out. The solid-state Q-band spectra (Figure S4) were by and large similar to the X-band ones, but they revealed additional features of the two subcomponents (Figure 8). In particular, the signal attributed to $\left[\mathrm{Cu}(4-\mathrm{Ph}-\mathrm{pzH})_{4}\right]$ was found to be rhombic, with a small split in its $x$ and $y$ components, indiscernible in the $\mathrm{X}$-band experiments. The overall behavior observed in the $\mathrm{X}$-band spectra was confirmed, with a composite spectrum at $5 \mathrm{~K}$.

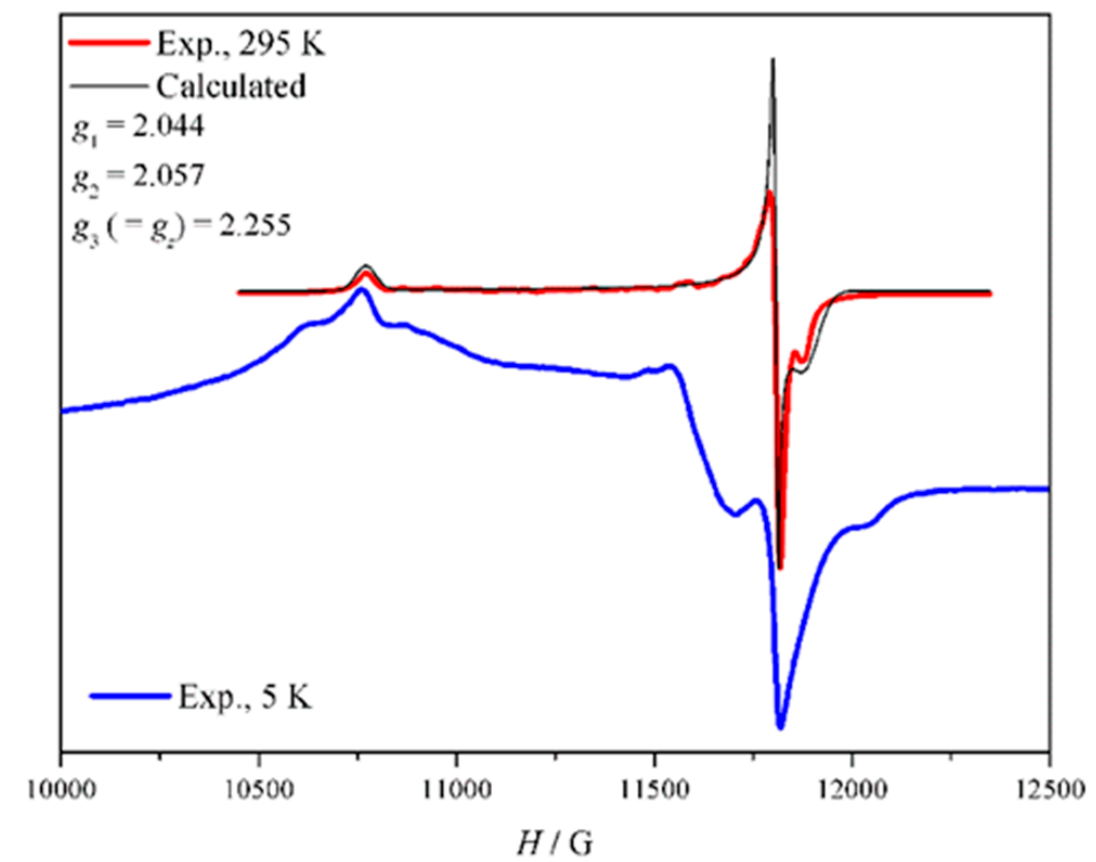

Figure 8. Q-band EPR spectra of (1) in a frozen THF solution (black line) and calculated curve according to the discussion in the text (red line). The blue and green lines correspond to the two components. Experimental conditions: $f_{\mathrm{EPR}}=33.96 \mathrm{GHz}, \mathrm{MA}=2 \mathrm{G}_{\mathrm{pp}}, P_{\mathrm{MW}}=0.29 \mathrm{~mW}(5 \mathrm{~K})$ and $1.1 \mathrm{~mW}(295 \mathrm{~K})$.

The solid-state structure is characterized by a network of possible dipolar interactions along the chains formed by the trinuclear and mononuclear complexes previously described (Figure S5). Depending on their magnetic symmetry, i.e., $|J|>\left|J^{\prime}\right|$ versus $|J|<\left|J^{\prime}\right|$, the spin densities of the triangles may be spread out over all three metal sites, or concentrated on one of them, respectively [13]. Our tentative conclusion from DFT calculation points toward the former case, which is also consistent with the magnetic susceptibility analysis, negating the applicability of the point-dipole approximation and hindering a straightforward analysis of dipolar interactions. Moreover, the non-trivial symmetry of the structure, combined with the extended nature of the system, seriously complicated any such analysis. Therefore, a detailed analysis of the dipole-dipole interactions was not pursued in this case.

\subsection{Theoretical DFT Calculations of (1)}

The complexity of magnetic interactions in (1) demands some theoretical insight guiding the analysis of the experimental magnetic data. Therefore, the isotropic exchange parameters $J_{i}$ were calculated with the help of broken-symmetry calculations using several molecular fragments derived from experimental X-ray data (Figure 9). First, the triangular moiety was extracted and energies of high-spin state (HS) and broken-symmetry spin states (BS) were calculated with B3LYP to derive $J$-parameters for spin Hamiltonian

$$
\hat{H}=-J_{12}\left(\mathbf{S}_{1} \cdot \mathbf{S}_{2}+\mathbf{S}_{1}, \cdot \mathbf{S}_{2 \prime}\right)-J_{13}\left(\mathbf{S}_{1} \cdot \mathbf{S}_{3}+\mathbf{S}_{1}, \cdot \mathbf{S}_{3 \prime}\right)-J_{23}\left(\mathbf{S}_{2} \cdot \mathbf{S}_{3}+\mathbf{S}_{2}, \cdot \mathbf{S}_{3 \prime}\right)
$$


(a)

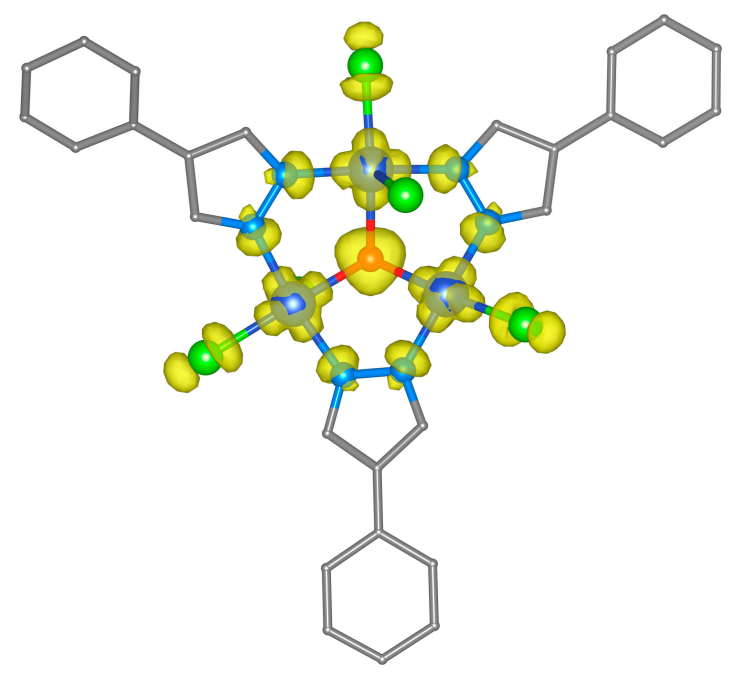

(b)

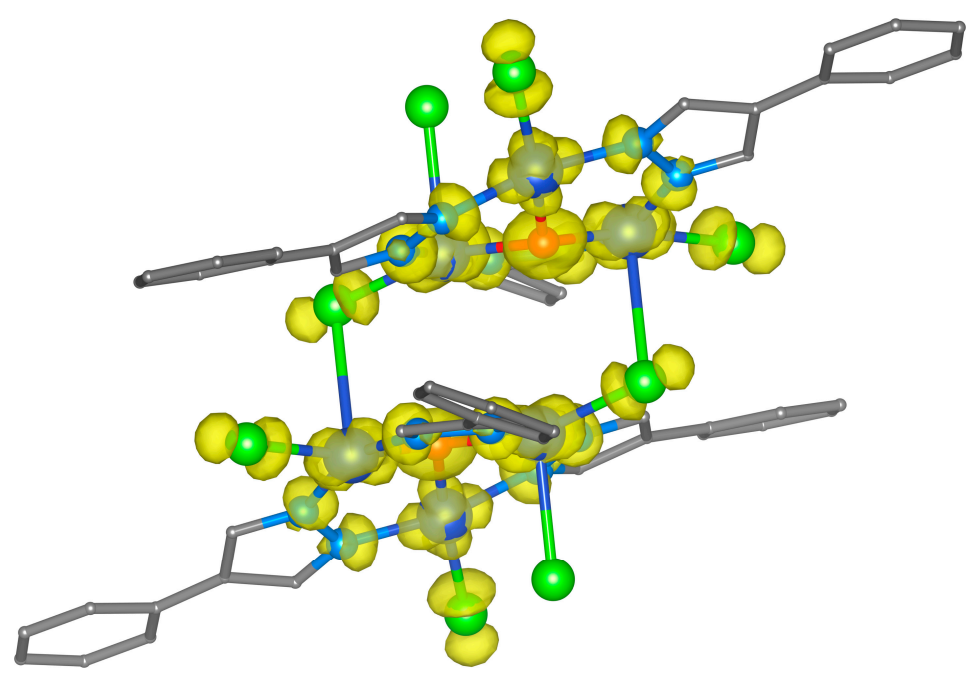

(c)

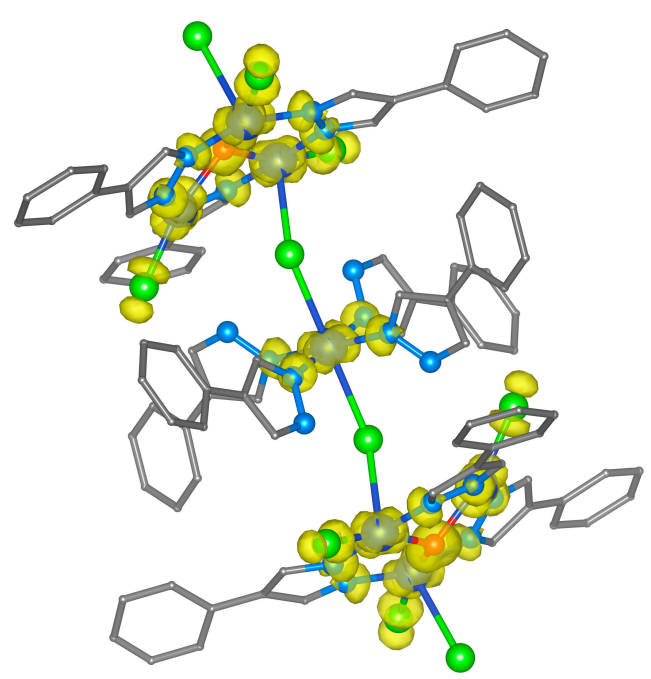

Figure 9. The calculated spin density distribution using B3LYP of (1) for the HS states of $\mathrm{Cu}_{3}$ molecular fragment (a), $\mathrm{Cu}_{6}$ fragment (b) and $\mathrm{Cu}_{7}$ fragment (c). The spin density is represented by yellow surfaces. The isodensity surfaces are plotted with the cut-off value of $0.005 e a_{0}{ }^{-3}$. Hydrogen atoms are omitted for clarity. 
As a result, the energies $\Delta_{1}=-245.197 \mathrm{~cm}^{-1}, \Delta_{2}=-323.346 \mathrm{~cm}^{-1}$ and $\Delta_{3}=-251.072 \mathrm{~cm}^{-1}$ were calculated, where $\Delta_{i}=\varepsilon_{\mathrm{BS}, \mathrm{i}}-\varepsilon_{\mathrm{HS}}$. From these energies, J-values were calculated by Ruiz's approach [54,55], resulting in $J_{12}=-159 \mathrm{~cm}^{-1}, J_{13}=-86.5 \mathrm{~cm}^{-1}$ and $J_{23}=-165 \mathrm{~cm}^{-1}$. It must be noted that this approach is based on the so-called strong interaction limit, whereas the weak interaction limit treatment of Noodleman would have resulted in $J$-values generally twice larger [56]. Next, the hexanuclear molecular fragment was extracted in order to estimate the magnetic exchange mediated by chlorido-ligands between two trimeric units:

$$
\hat{H}=-J_{12}\left(\mathbf{S}_{1} \cdot \mathbf{S}_{2}+\mathbf{S}_{1}, \cdot \mathbf{S}_{2 \prime}\right)-J_{13}\left(\mathbf{S}_{1} \cdot \mathbf{S}_{3}+\mathbf{S}_{1}, \cdot \mathbf{S}_{3 \prime}\right)-J_{23}\left(\mathbf{S}_{2} \cdot \mathbf{S}_{3}+\mathbf{S}_{2 \prime} \cdot \mathbf{S}_{3 \prime}\right)-J_{12}\left(\mathbf{S}_{1} \cdot \mathbf{S}_{2 \prime}+\mathbf{S}_{1}, \cdot \mathbf{S}_{2}\right)
$$

Therefore, energies of HS and BS123 states were calculated, leading to $\Delta_{123}=+5.808 \mathrm{~cm}^{-1}$, from which $J_{12^{\prime}}$ equals $+2.90 \mathrm{~cm}^{-1}$. Finally, the heptanuclear molecular fragment was investigated using spin Hamiltonian

$$
\hat{H}=-J_{12}\left(\mathbf{S}_{1} \cdot \mathbf{S}_{2}+\mathbf{S}_{1}, \cdot \mathbf{S}_{2 \prime}\right)-J_{13}\left(\mathbf{S}_{1} \cdot \mathbf{S}_{3}+\mathbf{S}_{1}, \cdot \mathbf{S}_{3 \prime}\right)-J_{23}\left(\mathbf{S}_{2} \cdot \mathbf{S}_{3}+\mathbf{S}_{2 \prime} \cdot \mathbf{S}_{3 \prime}\right)-J_{14}\left(\mathbf{S}_{1} \cdot \mathbf{S}_{4}+\mathbf{S}_{1}, \cdot \mathbf{S}_{4}\right)
$$

and HS and BS4 spin states were calculated, resulting in $\Delta_{123}=+1.723 \mathrm{~cm}^{-1}$. Thus, also this interaction is weakly ferromagnetic, $J_{14}=+0.86 \mathrm{~cm}^{-1}$.

\subsection{Magnetic Susceptibility Studies of (2)}

The temperature dependence of effective magnetic moment data for compound (2) is depicted in Figure 10. The room temperature effective magnetic moment has value $3.1 \mu_{\mathrm{B}}$, which is relatively close to the theoretical value $3.0 \mu_{\mathrm{B}}$ for three non-interacting spins $s_{1}=s_{2}=s_{3}=1 / 2$ with $g=2.0$. Upon lowering the temperature, the effective magnetic moment continually decreases down to a value of $0.1 \mu_{\mathrm{B}}$ at 1.9 $\mathrm{K}$, indicating the presence of strong antiferromagnetic exchange interactions. The observed magnetic behavior of (2) can be rationalized on a qualitative level by assuming dominant antiferromagnetic exchange within each triangle, which leads to $s_{\text {eff }}=1 / 2$ ground spin state similarly to (1) and also supported by DFT (vide infra). These $\mathrm{Cu}_{3}$-triangles are then coupled within the infinite chain by azido ligands, which also mediate a weak antiferromagnetic exchange. Established magnetostructural correlations $[57,58]$ also suggest that the $\mathrm{Cu}-\mathrm{N}-\mathrm{Cu}$ angles of $115.0(2)$ and 105.9(2) ${ }^{\circ}$ should mediate an antiferromagnetic exchange. Thus, from the magnetic point of view, the coordination polymer of (2) can be simplified to 1D chain of the antiferromagnetically coupled $s_{\text {eff }}=1 / 2$ spins with this spin Hamiltonian:

$$
\hat{H}=-J \sum_{i=1}^{\infty} \mathbf{S}_{i} \cdot \mathbf{S}_{i+1}+\mu_{\mathrm{B}} \sum_{i=1}^{\infty} \mathbf{B} \cdot \mathbf{g}_{i} \cdot \mathbf{S}_{i}
$$

where $s_{i}=S_{\text {eff }}=1 / 2$. Fortunately, the analytical equation of the molar susceptibility for said system has already been derived by Johnston et al. [59] and the fitting procedure applied to the temperature dependence of the molar susceptibility of (2) resulted in $J=-53 \mathrm{~cm}^{-1}$ with $g=2.2$. The negative value of $J$ confirms the antiferromagnetic exchange among the trinuclear building block within the coordination polymer in contrast to DFT calculations, which suggest ferromagnetic exchange mediated by azido ligands. Moreover, the deviation of calculated values of the effective magnetic moment at temperatures higher than ca $60 \mathrm{~K}$ is attributed to fact that at such high temperature, the proposed approximation of $s_{\text {eff }}=1 / 2$ for each $\mathrm{Cu}_{3}$-triangle loses its validity, because the excited $s_{\text {eff }}=3 / 2$ state is also populated, explaining the higher values of the effective magnetic moment in comparison to the calculated ones. It must be noted that we have tried to employ spin Hamiltonian analogous to Equation1 also for (2), but the agreement with the experimental data was not achieved. Most probably, the case of both intra and inter $\mathrm{Cu}_{3}$-triangle antiferromagnetic exchange would demand expanding the spin Hamiltonian to contain more spin centers to better simulate the polymeric character of the compound, which is unfortunately prohibited by large dimension of the respective Hilbert space. 


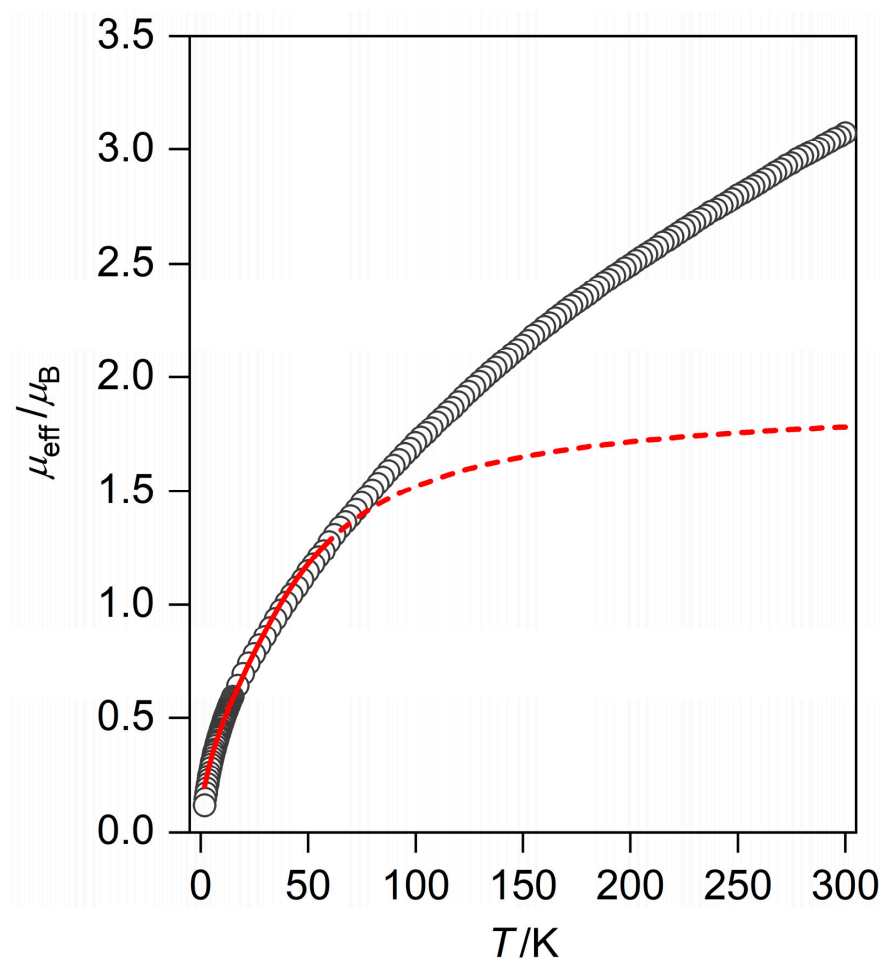

Figure 10. Temperature dependence of the effective magnetic moment for (2). The empty symbols-experimental data, the red line-calculated data with $J=-53 \mathrm{~cm}^{-1}$ and $g=2.2$ using spin Hamiltonian in Equation (2).

\subsection{EPR Spectroscopy of (2)}

The $4.2 \mathrm{~K}$ solid-state X-band EPR spectrum of (2) is characterized by a main derivative signal at $g=2.05$, and a secondary half-field transition at $g=4.06$; the latter transition was attributed to magnetic interactions with neighboring complexes of the polymeric structure (Figure 11). Due to the magnetic interaction pathway mediated by the bridging azides, which passes through non-magnetic orbitals of the copper(II) ions, this interaction may not be of exchange but of dipolar origins [60].

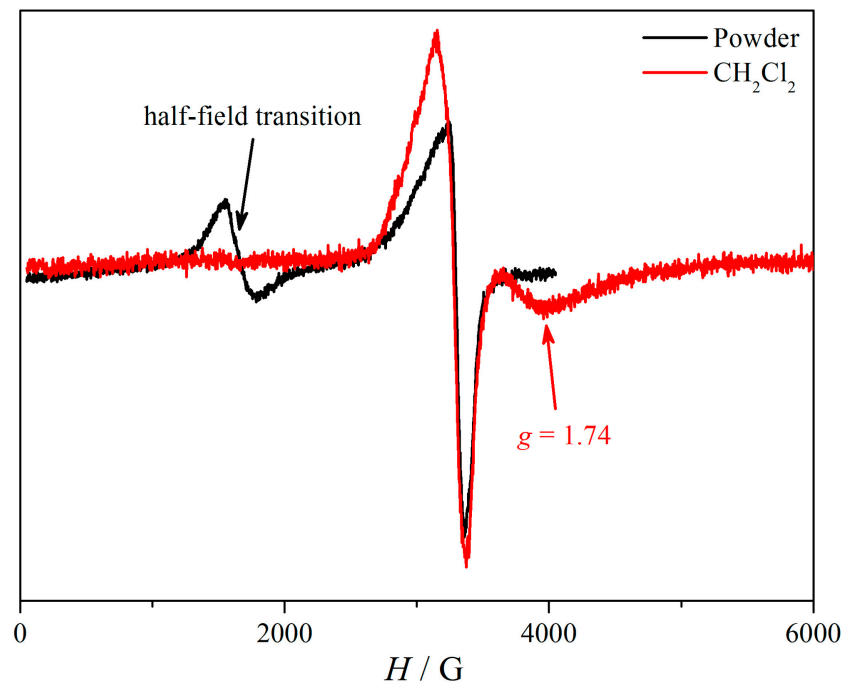

Figure 11. X-band EPR spectra of (2) in the solid state (black) and a frozen $\mathrm{CH}_{2} \mathrm{Cl}_{2}$ solution. Experimental parameters: $f_{\mathrm{EPR}}=9.429 \mathrm{GHz}, P_{M W}=2 \mathrm{~mW}, \mathrm{MA}=5 \mathrm{G}_{\mathrm{Pp}}$ (powder); and $f_{\mathrm{EPR}}=9.425 \mathrm{GHz}, P_{M W}=2 \mathrm{~mW}$, $\mathrm{MA}=2 \mathrm{G}_{\mathrm{pp}}$ (solution). 
In frozen $\mathrm{CH}_{2} \mathrm{Cl}_{2}$ solutions this half-field transition disappears, in line with a disruption of the polymeric network in solution. In turn, the solution spectrum exhibits a downfield shifted feature $(g=1.74)$, which is a characteristic signature of magnetic anisotropy induced by the combined operation of a moderate magnetic asymmetry $\left(J \neq J^{\prime}\right)$ and antisymmetric exchange interactions (Figure 10) $[13,52,53]$.

\subsection{Theoretical DFT Calculations of (2)}

The magnetic interactions in (2) were also analyzed with the broken-symmetry calculations using two molecular fragments derived from experimental X-ray data (Figure 12). First, the triangular moiety was extracted and energies of high-spin state (HS) and broken-symmetry spin states (BS) were calculated with B3LYP to derive J-parameters for spin Hamiltonian

$$
\hat{H}=-J_{12}\left(\mathbf{S}_{1} \cdot \mathbf{S}_{2}+\mathbf{S}_{1}, \cdot \mathbf{S}_{2 \prime}\right)-J_{13}\left(\mathbf{S}_{1} \cdot \mathbf{S}_{3}+\mathbf{S}_{1}, \mathbf{S}_{3 \prime}\right)-J_{23}\left(\mathbf{S}_{2} \cdot \mathbf{S}_{3}+\mathbf{S}_{2 \prime}, \mathbf{S}_{3 \prime}\right)
$$

(a)

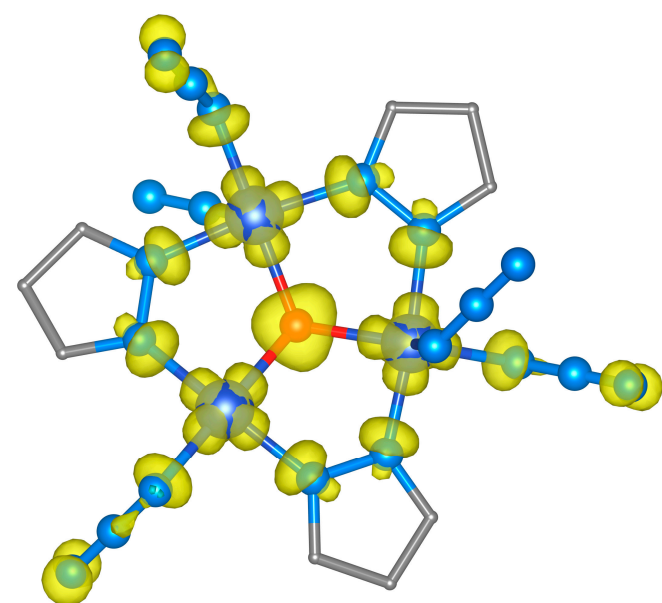

(b)

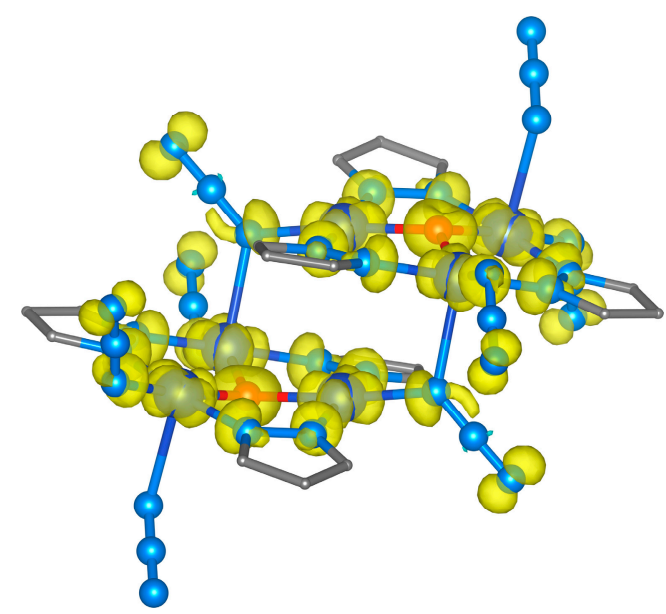

Figure 12. The calculated spin density distribution using B3LYP of (2) for the HS states of $\mathrm{Cu}_{3}$ molecular fragment (a) and $\mathrm{Cu}_{6}$ fragment $(\mathbf{b})$. The spin density is represented by yellow surfaces. The isodensity surfaces are plotted with the cut-off value of $0.005 \mathrm{ea}_{0}{ }^{-3}$. Hydrogen atoms are omitted for clarity.

As a result, the energies $\Delta_{1}=-337.724 \mathrm{~cm}^{-1}, \Delta_{2}=-362.944 \mathrm{~cm}^{-1}$ and $\Delta_{3}=-349.454 \mathrm{~cm}^{-1}$ were computed. Next, $J$-values were calculated by Ruiz's approach, as for (1), resulting in $J_{12}=-176 \mathrm{~cm}^{-1}$, $J_{13}=-162 \mathrm{~cm}^{-1}$ and $J_{23}=-187 \mathrm{~cm}^{-1}$. It should also be stressed that in weak interactions, limit $J$-values 
would have been two times larger. Afterwards, the hexamer molecular fragment was extracted in order to estimate the magnetic exchange mediated by azido-ligands between two trimeric units:

$$
\hat{H}=-J_{12}\left(\mathbf{S}_{1} \cdot \mathbf{S}_{2}+\mathbf{S}_{1}, \cdot \mathbf{S}_{2 \prime}\right)-J_{13}\left(\mathbf{S}_{1} \cdot \mathbf{S}_{3}+\mathbf{S}_{1}, \cdot \mathbf{S}_{3 \prime}\right)-J_{23}\left(\mathbf{S}_{2} \cdot \mathbf{S}_{3}+\mathbf{S}_{2,} \cdot \mathbf{S}_{3 \prime}\right)-J_{23 \prime}\left(\mathbf{S}_{2} \cdot \mathbf{S}_{3 \prime}+\mathbf{S}_{2 \prime} \cdot \mathbf{S}_{3}\right)
$$

Thus, energies of HS and BS123 states were calculated, leading to $\Delta_{123}=+10.644 \mathrm{~cm}^{-1}$, from which $J_{23^{\prime}}$ equals $+5.32 \mathrm{~cm}^{-1}$.

\section{Conclusions}

The one-dimensional solid state structures of (1) and (2) are held together by weak interactions via bridging anions-chlorides and azides, respectively—which are disrupted in solution. Because of the polymeric nature and low symmetry of these materials, the analysis of the magnetic properties has been supported by DFT calculations, suggesting strong antiferromagnetic exchange within $\mathrm{Cu}_{3}$ units and weak ferromagnetic interactions among these units. The predominant antiferromagnetic exchange within the $\mathrm{Cu}_{3}$ units has been unequivocally determined in both cases by the analysis of magnetic susceptibility characteristics. In addition, the operation of an antisymmetric exchange in (1) was evident by both magnetometry and EPR spectroscopy. The much weaker inter- $\mathrm{Cu}_{3}$ exchange, ferromagnetic in (1) and antiferromagnetic in (2), is attributed to the fact that non-magnetic Cu-orbitals are involved at one or both ends. EPR spectroscopy determined the magnitude of dipolar interaction in solid state (1), while the possible dipolar interaction between $\mathrm{Cu}_{3}$-units of (2) cannot be determined with certainty. The solution EPR spectra of both compounds are clearly distinguished from those in the solid state and are straightforwardly attributed to individual $\mathrm{Cu}_{3}\left(\mu_{3}-\mathrm{OH}\right)$ species of (2), and to the presence of isolated mononuclear and trinuclear species in the case of (1). Two new reports, describing the magnetic susceptibilities and (in one case) the EPR spectrum of polymeric supramolecular assemblies of copper(II) complexes, appeared in the literature recently [61,62].

Supplementary Materials: The following are available online at http://www.mdpi.com/2624-8549/2/3/39/s1. Table S1: Crystallographic and refinement data for (1) and (2). Table S2: Selected interatomic distances $(\AA)$ and angles $\left({ }^{\circ}\right)$ for $(\mathbf{1})$. Table S3: Selected interatomic distances $(\AA)$ and angles $\left(^{\circ}\right)$ for $(2)$ Figure S1: ORTEP diagram of (1). Figure S2: ORTEP diagram of (2). Figure S3: Infrared spectrum of (2). Figure S4: Solid-state X-band EPR spectra of (1) between 5 and $295 \mathrm{~K}$. Figure S5: Dipolar exchange scheme indicating the symmetry codes of the spins $\mathrm{Si}(\mathrm{i}=1-4)$ and the main intermolecular distances of $(\mathbf{1})$. The crystallographic data for this paper (CCDC 2005300 and 2005301) can also be obtained free of charge via www.ccdc.cam.ac.uk/data_request/cif, by emailing data_request@ccdc.cam.ac.uk, or by contacting The Cambridge Crystallographic Data Centre, 12 Union Road, Cambridge CB2 1EZ, UK; Fax: +44 1223336033.

Author Contributions: Conceptualization, R.G.R.; formal analysis, L.M., R.H. and A.K.B.; investigation, K.S., L.M., R.H. and A.K.B.; writing-original draft preparation, K.S., L.M., R.H. and A.K.B.; writing-review and editing, L.M., R.H., A.K.B. and R.G.R. All authors have read and agreed to the published version of the manuscript.

Funding: Research at FIU was funded partially by the National Science Foundation, grant number CHE-1213683. R.H. acknowledges the financial support from institutional sources of the Department of Inorganic Chemistry, Palacky University in Olomouc, Czech Republic, and from the National Programme of Sustainability I (LO1305) of the Ministry of Education, Youth and Sports of the Czech Republic.

Acknowledgments: We thank Philippe Turek for support throughout this study.

Conflicts of Interest: The authors declare no conflict of interest.

\section{References}

1. Pascual-Colino, J.; Beobide, G.; Castillo, O.; Lodewyckx, P.; Luque, A.; Pérez-Yáñez, S.; Román, P.; Velasco, L.F. Adenine nucleobase directed supramolecular architectures based on ferrimagnetic heptanuclear copper(II) entities and benzenecarboxylate anions. J. Inorg. Biochem. 2020, 202, 110865. [CrossRef]

2. González, M.M.; Osiry, H.; Martínez, M.; Rodríguez-Hernández, J.; Lemus-Santana, A.A.; Reguera, E. Magnetic interaction in a 2D solid through hydrogen bonds and $\pi-\pi$ stacking. J. Magn. Magn. Mater. 2019, 471, 70-76. [CrossRef] 
3. Pham, C.T.; Nguyen, T.H.; Matsumoto, K.; Nguyen, H.H. CuI/CuII Complexes with Dipicolinoylbis(N,N-diethylthiourea): Structures, Magnetism, and Guest Ion Exchange. Eur. J. Inorg. Chem. 2019, 2019, 4142-4146. [CrossRef]

4. Chi, Y.-H.; Yu, L.; Shi, J.-M.; Zhang, Y.-Q.; Hu, T.-Q.; Zhang, G.-Q.; Shi, W.; Cheng, P. $\pi-\pi$ Stacking and ferromagnetic coupling mechanism on a binuclear $\mathrm{Cu}(\mathrm{ii})$ complex. Dalton Trans. 2011, 40, 1453. [CrossRef] [PubMed]

5. Ehlert, M.K.; Rettig, S.J.; Storr, A.; Thompson, R.C.; Trotter, J. Metal pyrazolate polymers. Part 1. Synthesis, structure, and magnetic properties of the [Cu(pz)2]x polymer. Can. J. Chem. 1989, 67, 1970-1974. [CrossRef]

6. Ehlert, M.K.; Rettig, S.J.; Storr, A.; Thompson, R.C.; Trotter, J. Metal pyrazolate polymers. Part 2. Synthesis, structure, and magnetic properties of $[\mathrm{Cu}(4-\mathrm{Xpz}) 2]$ x polymers (where $\mathrm{X}=\mathrm{Cl}, \mathrm{Br}, \mathrm{Me}, \mathrm{H} ; \mathrm{pz}=$ pyrazolate). Can. J. Chem. 1991, 69, 432-439. [CrossRef]

7. Zueva, E.M.; Petrova, M.M.; Herchel, R.; Trávníček, Z.; Raptis, R.G.; Mathivathanan, L.; McGrady, J.E. Electronic structure and magnetic properties of a trigonal prismatic Cull6 cluster. Dalton Trans. 2009, 30, 5924-5932. [CrossRef] [PubMed]

8. Ferrer, S.; Lloret, F.; Bertomeu, I.; Alzuet, G.; Borrás, J.; García-Granda, S.; Liu-González, M.; Haasnoot, J.G. Cyclic Trinuclear and Chain of Cyclic Trinuclear Copper(II) Complexes Containing a Pyramidal $\mathrm{Cu} 3 \mathrm{O}(\mathrm{H})$ Core. Crystal Structures and Magnetic Properties of $\left[\mathrm{Cu}_{3}\left(\mu_{3}-\mathrm{OH}\right)(\text { aaat })_{3}(\mathrm{H} 2 \mathrm{O})_{3}\right]\left(\mathrm{NO}_{3}\right)_{2} \cdot \mathrm{H}_{2} \mathrm{O}$ [aaat $=3$-Acetylamino-5-amino-1,2,4-triazolate $]$ and $\left\{\left[\mathrm{Cu}_{3}\left(\mu_{3}-\mathrm{OH}\right)(\text { aat })_{3}\left(\mu_{3}-\mathrm{SO}_{4}\right)\right] \cdot 6 \mathrm{H}_{2} \mathrm{O}\right\}_{\mathrm{n}}$ [aat = 3-Acetylamino-1,2,4-triazolate]: New Cases of Spin-Frustrated Systems. Inorg. Chem. 2002, 41, 5821-5830. [CrossRef]

9. Ferrer, S.; Lloret, F.; Pardo, E.; Clemente-Juan, J.M.; Liu-González, M.; García-Granda, S. Antisymmetric Exchange in Triangular Tricopper(II) Complexes: Correlation among Structural, Magnetic, and Electron Paramagnetic Resonance Parameters. Inorg. Chem. 2012, 51, 985-1001. [CrossRef]

10. Belinsky, M.I. Hyperfine Splittings in Spin-Frustrated Trinuclear $\mathrm{Cu}_{3}$ Clusters. Inorg. Chem. 2004, 43, 739-746. [CrossRef]

11. Boča, R.; Dlháň, L.; Mezei, G.; Ortiz-Pérez, T.; Raptis, R.G.; Telser, J. Triangular, Ferromagnetically-Coupled CuII3-Pyrazolato Complexes as Possible Models of Particulate Methane Monooxygenase (pMMO). Inorg. Chem. 2003, 42, 5801-5803. [CrossRef] [PubMed]

12. Angaridis, P.A.; Baran, P.; Boča, R.; Cervantes-Lee, F.; Haase, W.; Mezei, G.; Raptis, R.G.; Werner, R. Synthesis and Structural Characterization of Trinuclear CuII-Pyrazolato Complexes Containing $\mu_{3}-\mathrm{OH}$, $\mu_{3}-\mathrm{O}$, and $\mu_{3}-\mathrm{Cl}$ Ligands. Magnetic Susceptibility Study of $[\mathrm{PPN}]_{2}\left[\left(\mu_{3}-\mathrm{O}\right) \mathrm{Cu}_{3}(\mu-\mathrm{pz})_{3} \mathrm{Cl}_{3}\right]$. Inorg. Chem. 2002, 41, 2219-2228. [CrossRef] [PubMed]

13. Mathivathanan, L.; Boudalis, A.K.; Turek, P.; Pissas, M.; Sanakis, Y.; Raptis, R.G. Interactions between H-bonded $\left[\mathrm{CuII}_{3}\left(\mu_{3}-\mathrm{OH}\right)\right]$ triangles; a combined magnetic susceptibility and EPR study. Phys. Chem. Chem. Phys. 2018, 20, 17234-17244. [CrossRef] [PubMed]

14. Olguín, J.; Brooker, S. Synthesis of 3- and 5-formyl-4-phenyl-1H-pyrazoles: Promising head units for the generation of asymmetric imine ligands and mixed metal polynuclear complexes. New J. Chem. 2011, 35, 1242-1253. [CrossRef]

15. Armarego, W.L.F.; Chai, C.L.L. Purification of Laboratory Chemicals, 7th ed.; Elsevier/Butterworth-Heinemann: Amsterdam, The Netherlands; London, UK, 2013; ISBN 978-0-12-382161-4.

16. APEX3; Bruker AXS Inc.: Madisson, WI, USA, 2017.

17. SADABS; Bruker AXS Inc.: Madisson, WI, USA, 2001.

18. Sheldrick, G.M. SHELXT-Integrated space-group and crystal-structure determination. Acta Crystallogr. Sect. A Found. Adv. 2015, 71, 3-8. [CrossRef]

19. Sheldrick, G.M. Crystal Structure refinement with SHELXL. Acta Crystallogr. Sect. C Struct. Chem. 2015, 71, 3-8. [CrossRef] [PubMed]

20. Dolomanov, O.V.; Bourhis, L.J.; Gildea, R.J.; Howard, J.A.K.; Puschmann, H. OLEX2: A complete structure solution, refinement and analysis program. J. Appl. Crystallogr. 2009, 42, 339-341. [CrossRef]

21. Spek, A.L. Structure validation in chemical crystallography. Acta Crystallogr. D Biol. Crystallogr. 2009, 65, 148-155. [CrossRef]

22. Thorn, A.; Dittrich, B.; Sheldrick, G.M. Enhanced rigid-bond restraints. Acta Crystallogr. A 2012, 68, $448-451$. [CrossRef]

23. Herchel, R.; Boča, R. Program Polymagnet; Slovak Technical University: Bratislava, Slovakia, 2006-2020. 
24. Neese, F. The ORCA program system. WIREs Comput. Mol. Sci. 2012, 2, 73-78. [CrossRef]

25. Becke, A.D. Density-functional exchange-energy approximation with correct asymptotic behavior. Phys. Rev. A 1988, 38, 3098-3100. [CrossRef] [PubMed]

26. Lee, C.; Yang, W.; Parr, R.G. Development of the Colle-Salvetti correlation-energy formula into a functional of the electron density. Phys. Rev. B 1988, 37, 785-789. [CrossRef] [PubMed]

27. Stephens, P.J.; Devlin, F.J.; Chabalowski, C.F.; Frisch, M.J. Ab Initio Calculation of Vibrational Absorption and Circular Dichroism Spectra Using Density Functional Force Fields. J. Phys. Chem. 1994, 98, 11623-11627. [CrossRef]

28. Weigend, F.; Ahlrichs, R. Balanced basis sets of split valence, triple zeta valence and quadruple zeta valence quality for H to Rn: Design and assessment of accuracy. Phys. Chem. Chem. Phys. 2005, 7, 3297-3305. [CrossRef]

29. Neese, F.; Wennmohs, F.; Hansen, A.; Becker, U. Efficient, approximate and parallel Hartree-Fock and hybrid DFT calculations. A 'chain-of-spheres' algorithm for the Hartree-Fock exchange. Chem. Phys. 2009, 356, 98-109. [CrossRef]

30. Izsák, R.; Neese, F. An overlap fitted chain of spheres exchange method. J. Chem. Phys. 2011, 135, 144105. [CrossRef] [PubMed]

31. Weigend, F. Accurate Coulomb-fitting basis sets for H to Rn. Phys. Chem. Chem. Phys. 2006, 8, 1057-1065. [CrossRef]

32. Momma, K.; Izumi, F. VESTA 3 for three-dimensional visualization of crystal, volumetric and morphology data. J. Appl. Crystallogr. 2011, 44, 1272-1276. [CrossRef]

33. Shi, K.; Mathivathanan, L.; Boudalis, A.K.; Turek, P.; Chakraborty, I.; Raptis, R.G. Nitrite Reduction by Trinuclear Copper Pyrazolate Complexes: An Example of a Catalytic, Synthetic Polynuclear NO Releasing System. Inorg. Chem. 2019. [CrossRef]

34. Casarin, M.; Cingolani, A.; Di Nicola, C.; Falcomer, D.; Monari, M.; Pandolfo, L.; Pettinari, C. The Different Supramolecular Arrangements of the Triangular $\left[\mathrm{Cu}_{3}\left(\mu_{3}-\mathrm{OH}\right)(\mu-\mathrm{pz})_{3}\right]^{2+}(\mathrm{pz}=$ Pyrazolate) Secondary Building Units. Synthesis of a Coordination Polymer with Permanent Hexagonal Channels. Cryst. Growth Des. 2007, 7, 676-685. [CrossRef]

35. Direm, A.; Tursun, M.; Parlak, C.; Benali-Cherif, N. Trans-dichlorotetrakis(1H-pyrazole- $\left.\mathrm{KN}_{2}\right) \operatorname{copper}(\mathrm{II})$ : Synthesis, crystal structure, hydrogen bonding graph-sets, vibrational and DFT studies. J. Mol. Struct. 2015, 1093, 208-218. [CrossRef]

36. Sun, Y.-J.; Cheng, P.; Yan, S.-P.; Liao, D.-Z.; Jiang, Z.-H.; Shen, P.-W. Synthesis, crystal structure and properties of copper(II) complexes with different axial ligands and substituted pyrazoles. J. Mol. Struct. 2001, 597, 191-198. [CrossRef]

37. Małecka, M.; Chęcińska, L. Di chloro tetrakis(3-phenyl pyrazole- $\mathrm{N}_{2}$ )copper(II). Acta Crystallogr. C 2003, 59, m115-m117. [CrossRef] [PubMed]

38. Adak, P.; Das, C.; Ghosh, B.; Mondal, S.; Pakhira, B.; Sinn, E.; Blake, A.J.; O'Connor, A.E.; Chattopadhyay, S.K. Two pseudohalide-bridged $\mathrm{Cu}(\mathrm{II})$ complexes bearing the anthracene moiety: Synthesis, crystal structures and catecholase-like activity. Polyhedron 2016, 119, 39-48. [CrossRef]

39. Ray, M.S.; Ghosh, A.; Bhattacharya, R.; Mukhopadhyay, G.; Drew, M.G.B.; Ribas, J. Different supramolecular hydrogen bond structures and significant changes in magnetic properties in dinuclear $\mu_{2}-1,1-\mathrm{N}_{3}$ copper(II) complexes with very similar tridentate Schiff base blocking ligands. Dalton Trans. 2004. [CrossRef] [PubMed]

40. Boča, R.; Herchel, R. Antisymmetric exchange in polynuclear metal complexes. Coord. Chem. Rev. 2010, 254, 2973-3025. [CrossRef]

41. Mathivathanan, L.; Al-Ameed, K.; Lazarou, K.; Trávníček, Z.; Sanakis, Y.; Herchel, R.; McGrady, J.E.; Raptis, R.G. A trigonal prismatic Cu6-pyrazolato complex containing a $\mu_{6}$-F ligand. Dalton Trans. 2015, 44, 20685-20691. [CrossRef]

42. Moriya, T. Anisotropic Superexchange Interaction and Weak Ferromagnetism. Phys. Rev. 1960, 120, 91-98. [CrossRef]

43. Kahn, O. Molecular Magnetism; VCH: New York, NY, USA, 1993; ISBN 978-1-56081-566-2.

44. Zheng, L.-L.; Leng, J.-D.; Zheng, S.-L.; Zhaxi, Y.-C.; Zhang, W.-X.; Tong, M.-L. Engineering delocalizing $\pi$ electronic $\left[\mathrm{CuII} 3\left(\mu_{3}-\mathrm{OH}\right)(\mu-\mathrm{pz})_{3}\right]^{2+}$ species into organometallic frameworks by Ag- $\pi$ coordination. CrystEngComm 2008, 10, 1467. [CrossRef] 
45. Hulsbergen, F.B.; ten Hoedt, R.W.M.; Verschoor, G.C.; Reedijk, J.; Spek, A.L. Synthesis, magnetic properties, and X-ray structure of catena- $\mu_{3}$-nitrato-O, $\mathrm{O}^{\prime}, \mathrm{O}^{\prime \prime}$-[ $\left[\mu_{3}\right.$-hydroxo-1-nitrato-1,2;1,3;2,3-tris $(\mu$ pyrazolato-N, $\mathrm{N}^{\prime}$ )-2,3-bis(pyrazole- $\mathrm{N}_{2}$ )tricopper(II) monohydrate]. An unusual chain of trinuclear copper clusters. J. Chem. Soc. Dalton Trans. 1983. [CrossRef]

46. Angaroni, M.; Ardizzoia, G.A.; Beringhelli, T.; Monica, G.L.; Gatteschi, D.; Masciocchi, N.; Moret, M. Oxidation reaction of $\left[\left\{\mathrm{Cu}(\mathrm{Hpz})_{2} \mathrm{Cl}_{2}\right](\mathrm{Hpz}=\right.$ pyrazole): Synthesis of the trinuclear copper(II) hydroxo complexes $\left[\mathrm{Cu}_{3}(\mathrm{OH})(\mathrm{pz})_{3}(\mathrm{Hpz})_{2} \mathrm{Cl}_{2}\right] \cdot \mathrm{solv}$ (solv $=\mathrm{H}_{2} \mathrm{O}$ or tetrahydrofuran). Formation, magnetic properties, and X-ray crystal structure of $\left[\mathrm{Cu}_{3}(\mathrm{OH})(\mathrm{pz})_{3}(\mathrm{py})_{2} \mathrm{Cl}_{2}\right] \cdot \mathrm{py}$ (py = pyridine). J. Chem. Soc. Dalton Trans. 1990. [CrossRef]

47. Ferrer, S.; Haasnoot, J.G.; Reedijk, J.; Müller, E.; Biagini Cingi, M.; Lanfranchi, M.; Manotti Lanfredi, A.M.; Ribas, J. Trinuclear N,N-Bridged Copper(II) Complexes Involving a $\mathrm{Cu}_{3} \mathrm{OH}$ Core: $\left[\mathrm{Cu}_{3}\left(\mu_{3^{-}}\right.\right.$ $\left.\mathrm{OH}) \mathrm{L}_{3} \mathrm{~A}\left(\mathrm{H}_{2} \mathrm{O}\right)_{2}\right] \mathrm{A}\left(\mathrm{H}_{2} \mathrm{O}\right)_{x}\left\{\mathrm{~L}=3\right.$-Acetylamino-1,2,4-triazolate; $\left.\mathrm{A}=\mathrm{CF}_{3} \mathrm{SO}_{3}, \mathrm{NO}_{3}, \mathrm{ClO}_{4} ; x=0,2\right\}$ Synthesis, $\mathrm{X}$-ray Structures, Spectroscopy, and Magnetic Properties. Inorg. Chem. 2000, 39, 1859-1867. [CrossRef] [PubMed]

48. Ding, B.; Yi, L.; Cheng, P.; Liao, D.-Z.; Yan, S.-P. Synthesis and Characterization of a 3D Coordination Polymer Based on Trinuclear Triangular CuII as Secondary Building Units. Inorg. Chem. 2006, 45, 5799-5803. [CrossRef] [PubMed]

49. Ouellette, W.; Prosvirin, A.V.; Chieffo, V.; Dunbar, K.R.; Hudson, B.; Zubieta, J. Solid-State Coordination Chemistry of the $\mathrm{Cu}$ /Triazolate/ $\mathrm{X}$ System $\left(\mathrm{X}=\mathrm{F}^{-}, \mathrm{Cl}^{-}, \mathrm{Br}^{-}, \mathrm{I}^{-}, \mathrm{OH}^{-}\right.$, and $\left.\mathrm{SO}_{4}{ }^{2-}\right)$. Inorg. Chem. 2006, 45, 9346-9366. [CrossRef] [PubMed]

50. Liu, X.; de Miranda, M.P.; McInnes, E.J.L.; Kilner, C.A.; Halcrow, M.A. Antisymmetric exchange in two tricopper(II) complexes containing a $\left[\mathrm{Cu}_{3}\left(\mu_{3}-\mathrm{OMe}\right)\right]^{5+}$ core. Dalton Trans. 2004. [CrossRef]

51. Liu, J.-C.; Guo, G.-C.; Huang, J.-S.; You, X.-Z. Different Oxidation States of Copper(I, I/II, II) Thiocyanate Complexes Containing 1,2,4-Triazole as a Bridging Ligand: Syntheses, Crystal Structures, and Magnetic Properties of 2-D Polymer CuI(admtrz)SCN, Linear Trinuclear [CuI ${ }_{2} \mathrm{CuII}(\mathrm{admtrz})_{6}$ $\left.(\mathrm{SCN})_{2}\right]\left(\mathrm{ClO}_{4}\right)_{2}$, and Triangular Trinuclear $\left[\mathrm{CuII}_{3}(\mathrm{admtrz})_{4}(\mathrm{SCN})_{3}\left(\mu_{3}-\mathrm{OH}\right)\left(\mathrm{H}_{2} \mathrm{O}\right)\right]\left(\mathrm{ClO}_{4}\right)_{2} \cdot \mathrm{H}_{2} \mathrm{O}(\mathrm{admtrz}=4-$ Amino-3,5-dimethyl-1,2,4-triazole). Inorg. Chem. 2003, 42, 235-243. [CrossRef] [PubMed]

52. Georgopoulou, A.N.; Margiolaki, I.; Psycharis, V.; Boudalis, A.K. Dynamic versus Static Character of the Magnetic Jahn-Teller Effect: Magnetostructural Studies of $\left[\mathrm{Fe}_{3} \mathrm{O}\left(\mathrm{O}_{2} \mathrm{CPh}\right)_{6}(\mathrm{py})_{3}\right] \mathrm{ClO}_{4}$ py. Inorg. Chem. 2017, 56, 762-772. [CrossRef] [PubMed]

53. Boudalis, A.K.; Rogez, G.; Turek, P. Determination of the Distributions of the Spin-Hamiltonian Parameters in Spin Triangles: A Combined Magnetic Susceptometry and Electron Paramagnetic Resonance Spectroscopic Study of the Highly Symmetric $\left[\mathrm{Cr}_{3} \mathrm{O}(\mathrm{PhCOO})_{6}(\mathrm{py})_{3}\right]\left(\mathrm{ClO}_{4}\right) \cdot 0.5 p y$. Inorg. Chem. 2018, 57, 13259-13269. [CrossRef]

54. Ruiz, E.; Cano, J.; Alvarez, S.; Alemany, P. Broken symmetry approach to calculation of exchange coupling constants for homobinuclear and heterobinuclear transition metal complexes. J. Comput. Chem. 1999, 20, 1391-1400. [CrossRef]

55. Ruiz, E.; Rodríguez-Fortea, A.; Cano, J.; Alvarez, S.; Alemany, P. About the calculation of exchange coupling constants in polynuclear transition metal complexes. J. Comput. Chem. 2003, 24, 982-989. [CrossRef]

56. Neese, F. Prediction of molecular properties and molecular spectroscopy with density functional theory: From fundamental theory to exchange-coupling. Coord. Chem. Rev. 2009, 253, 526-563. [CrossRef]

57. Hay, P.J.; Thibeault, J.C.; Hoffmann, R. Orbital interactions in metal dimer complexes. J. Am. Chem. Soc. 1975, 97, 4884-4899. [CrossRef]

58. Ruiz, E.; Alemany, P.; Alvarez, S.; Cano, J. Toward the Prediction of Magnetic Coupling in Molecular Systems: Hydroxo- and Alkoxo-Bridged Cu(II) Binuclear Complexes. J. Am. Chem. Soc. 1997, 119, 1297-1303. [CrossRef]

59. Johnston, D.C.; Kremer, R.K.; Troyer, M.; Wang, X.; Klümper, A.; Bud'ko, S.L.; Panchula, A.F.; Canfield, P.C. Thermodynamics of spin $\$ S=1 / 2 \$$ antiferromagnetic uniform and alternating-exchange Heisenberg chains. Phys. Rev. B 2000, 61, 9558-9606. [CrossRef]

60. Eaton, S.S.; More, K.M.; Sawant, B.M.; Eaton, G.R. Use of the ESR half-field transition to determine the interspin distance and the orientation of the interspin vector in systems with two unpaired electrons. J. Am. Chem. Soc. 1983, 105, 6560-6567. [CrossRef] 
61. Monroe, J.C.; Carvajal, M.A.; Deumal, M.; Landee, C.P.; Redemeyer, M.; Turnbull, M.M. Revisiting the Role of Hydrogen Bonding in the Strong Dimer Superexchange of a 2D Copper(II) Halide Honeycomb-Like Lattice: Structural and Magnetic Study. Inorg. Chem. 2020, 59, 6319-6331. [CrossRef] [PubMed]

62. Matos, C.R.M.; Junior, H.C.S.; D'Amato, D.L.; de Souza, A.C.; Pinheiro, S.; Guedes, G.P.; Ferreira, G.B.; Alves, O.C.; de Almeida, F.B.; Garcia, F.; et al. Spin-frustration with two quasi-degenerated spin states of a copper(II) heptanuclear complex obtained from an amino acid ligand. Dalton Trans. 2020. [CrossRef]

(C) 2020 by the authors. Licensee MDPI, Basel, Switzerland. This article is an open access article distributed under the terms and conditions of the Creative Commons Attribution (CC BY) license (http://creativecommons.org/licenses/by/4.0/). 